\title{
Exploring changes in female genital mutilation/cutting: Shifting norms and practices among communities in Fafan and West Arsi zones, Ethiopia
}

Getaneh Mehari

Asabneh Molla

Ayantu Mamo

Dennis Matanda

Population Council

Follow this and additional works at: https://knowledgecommons.popcouncil.org/departments_sbsr-rh

Part of the Demography, Population, and Ecology Commons, Family, Life Course, and Society

Commons, International Public Health Commons, and the Sociology of Culture Commons

How does access to this work benefit you? Let us know!

\section{Recommended Citation}

Mehari, Getaneh, Asabneh Molla, Ayantu Mamo, and Dennis Matanda. 2020. "Exploring changes in female genital mutilation/cutting: Shifting norms and practices among communities in Fafan and West Arsi zones, Ethiopia," Evidence to End FGM/C: Research to Help Girls and Women Thrive. New York: Population Council. 


\section{Evidence to End FGM/C}

\section{EXPLORING CHANGES IN FEMALE GENITAL MUTILATION/CUTTING: SHIFTING NORMS AND PRACTICES AMONG COMMUNITIES IN FAFAN AND WEST ARSI ZONES, ETHIOPIA}

April 2020 


\section{EXPLORING CHANGES IN FEMALE GENITAL MUTILATION/CUTTING: SHIFTING NORMS AND PRACTICES AMONG COMMUNITIES IN FAFAN AND WEST ARSI ZONES, ETHIOPIA}

GETANEH MEHARI ADDIS ABABA UNVERSITY

ASABNEH MOLLA ADDIS ABABA UNVERSITY

AYANTU MAMO WOLEGA UNIVERISTY

DENNIS MATANDA POPULATION COUNCIL 
Evidence to End FGM/C: Research to Help Girls and Women Thrive generates evidence to inform and influence investments, policies, and programmes for ending female genital mutilation/cutting in different contexts. Evidence to End FGM/C is led by the Population Council, Nairobi in partnership with the Africa Coordinating Centre for the Abandonment of Female Genital Mutilation/Cutting (ACCAF), Kenya; the Global Research and Advocacy Group (GRAG), Senegal; Population Council, Nigeria; Population Council, Egypt; Population Council, Ethiopia; Mannion Daniels, Ltd. (MD); Population Reference Bureau (PRB); University of California, San Diego (Dr. Gerry Mackie); and University of Washington, Seattle (Prof. Bettina Shell-Duncan).

POPULATION COUNCIL

Ideas. Evidence. Impact.
The Population Council confronts critical health and development issuesfrom stopping the spread of HIV to improving reproductive health and ensuring that young people lead full and productive lives. Through biomedical, social science, and public health research in 50 countries, we work with our partners to deliver solutions that lead to more effective policies, programmes, and technologies that improve lives around the world. Established in 1952 and headquartered in New York, the Council is a nongovernmental, nonprofit organisation governed by an international board of trustees. www.popcouncil.org

The Ethiopian Society of Sociologists, Social Workers and Anthropologists (ESSSWA) was founded in June 1996 as a professional society of Sociologists, Social Workers and Anthropologists with the objective of playing a facilitation role in tapping the potentials of these professions and its members in social development endeavours of the country. Its aims are to develop members' professional competence and enhance their contribution in addressing existing and emerging social issues.

Suggested Citation: Mehari Getaneh, Molla Asabneh, Mamo Ayantu, and Matanda Dennis. 2020. "Exploring Changes in Female Genital Mutilation/Cutting: Shifting Norms and Practices among Communities in Fafan and West Arsi Zones, Ethiopia." Evidence to End FGM/C: Research to Help Girls and Women Thrive. New York: Population Council.

This is a working paper and represents research in progress. This paper represents the opinions of the authors and is the product of professional research. This paper has not been peer reviewed, and this version may be updated with additional analyses in subsequent publications. Contact: getanehmeh@gmail.com

Please address any inquiries about the Evidence to End FGM/C programme consortium to:

Dr Jacinta Muteshi, Project Director, imuteshi@popcouncil.org

Funded by:

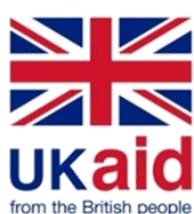

This document is output from a programme funded by UK Aid from the UK government for the benefit of developing countries. However, the views expressed and information contained in it are not necessarily those of, or endorsed by the UK government, which can accept no responsibility for such views or information or for any reliance placed on them. 


\section{Table of Contents}

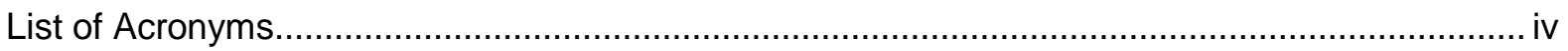

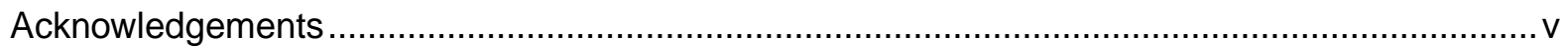

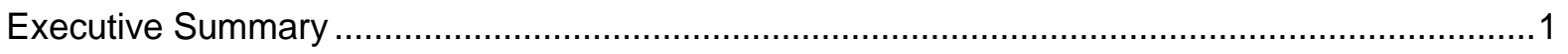

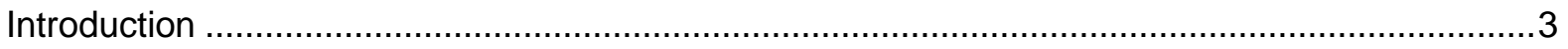

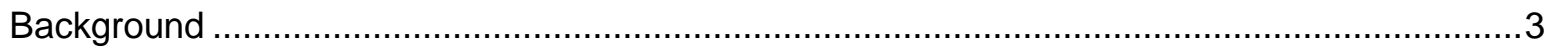

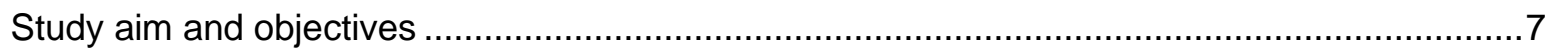

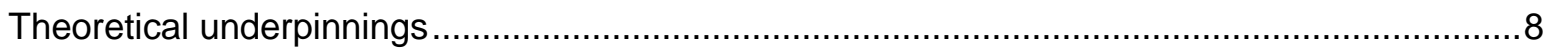

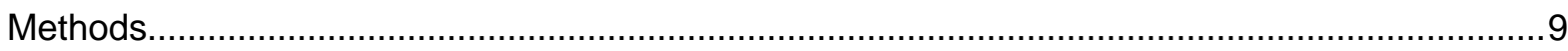

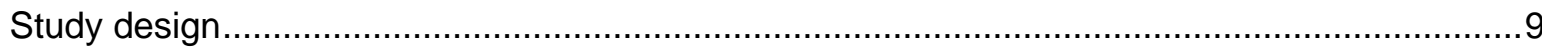

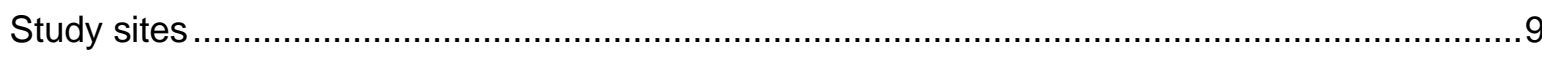

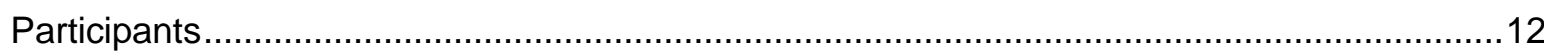

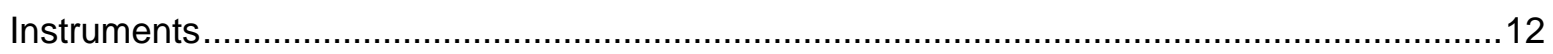

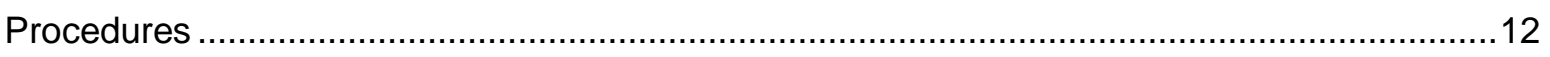

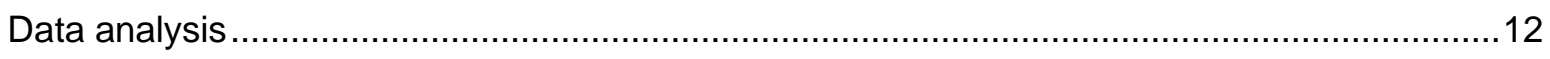

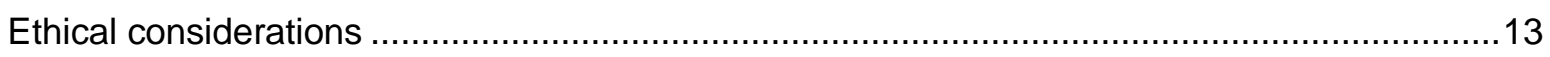

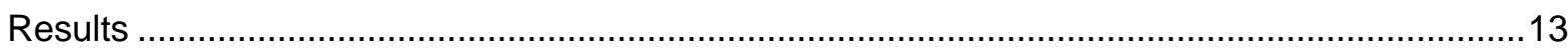

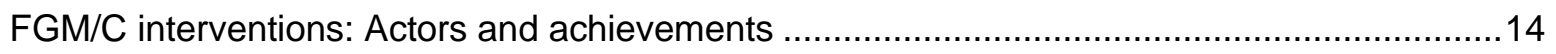

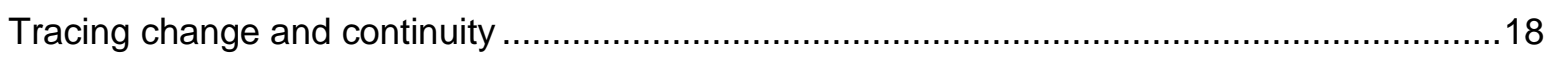

Knowledge on the consequences of FGM/C and acceptability of change ...............................23

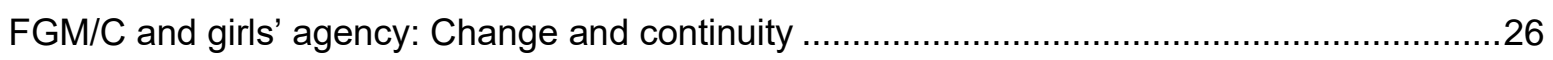

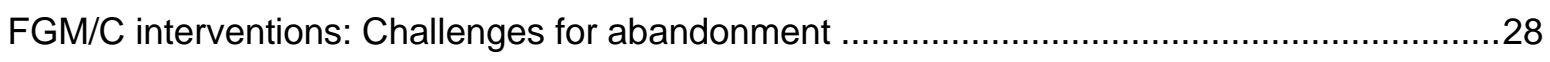

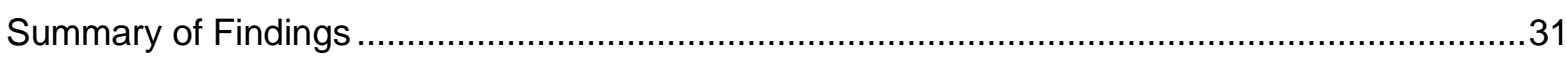

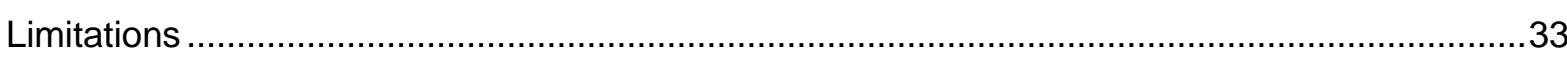

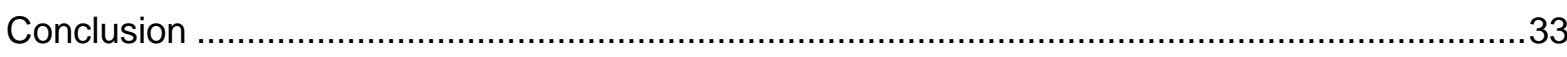

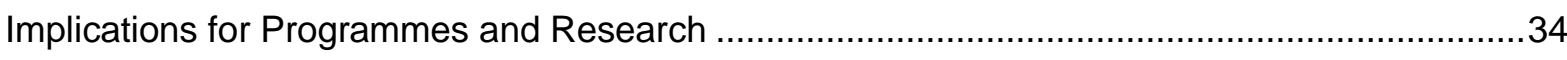

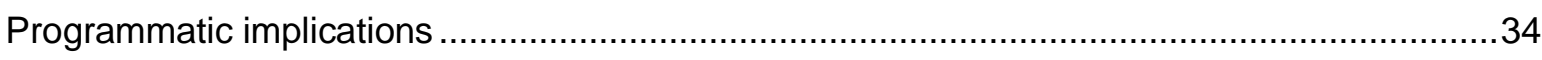

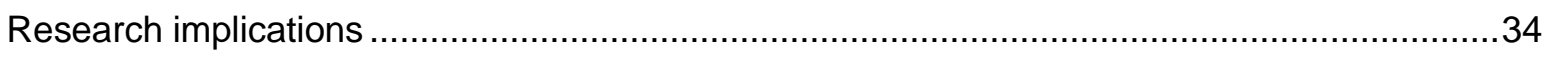

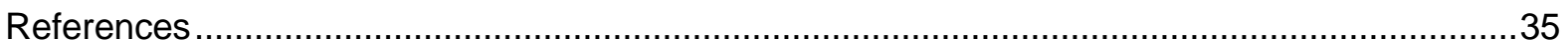




\section{List of Acronyms}

$\begin{array}{ll}\text { CSL } & \text { Charities and Societies Law } \\ \text { DFID } & \text { Department for International Development } \\ \text { EDHS } & \text { Ethiopia Demographic and Health Survey } \\ \text { ESSSWA } & \text { Ethiopian Society of Sociologists, Social Workers and Anthropologists } \\ \text { FBO } & \text { Faith-Based Organisation } \\ \text { FGD } & \text { Focus Group Discussion } \\ \text { FGM/C } & \text { Female Genital Mutilation/Cutting } \\ \text { HEW } & \text { Health Extension Worker } \\ \text { HTP } & \text { Harmful Traditional Practices } \\ \text { IDI } & \text { In-depth Interview } \\ \text { NGO } & \text { Nongovernmental Organisation } \\ \text { PI } & \text { Principal Investigator } \\ \text { SNNPR } & \text { Southern Nations, Nationalities, and Peoples Region } \\ \text { UNICEF } & \text { United Nations Children's Fund } \\ \text { WHO } & \text { World Health Organization }\end{array}$




\section{Acknowledgements}

This study would have not been successfully completed without the support of several individuals, communities and institutions. First, we would like to extend our deepest gratitude to Mr. Zelalem Anteneh and Mr. Sintayehu Dejene, former and current executive directors of the Ethiopian Society of Sociologists, Social Workers and Anthropologists (ESSSWA), for their continuous support from the inception of the research project to its completion. Our thanks also goes to Mr. Garedew Yilma, coordinator of the research project, for his contributions in organising the activities of the research project including trainings, meetings, and data collection. Data-collection teams of both sites also deserve many thanks for their contributions during the fieldwork activities. We extend our gratitude to the study communities, local guides, and study participants for their support and cooperation during our fieldwork. Several institutions also contributed to the successful completion of this study. Specifically, we appreciate the contributions of the Ministry of Women, Children, and Youth Affairs of the Federal Democratic Republic of Ethiopia; and women's affairs offices at the regional, zonal, and district levels in Oromia and Somali regional states.

Special thanks to Chimaraoke Izugbara of the International Center for Research on Women; and Chi-Chi Undie, Caroline Kabiru, and Jacinta Muteshi of the Population Council for reviewing and providing critical feedback to earlier drafts of the report. We appreciate additional technical and editorial support provided by Michelle Hindin of the Population Council. This study was funded by UK Aid from the UK government under the DFID research project "Evidence to End FGM/C: Research to Help Girls and Women Thrive." The study was coordinated and implemented by ESSSWA in collaboration with the Population Council. 


\section{Executive Summary}

\section{Background}

Globally, more than 200 million women and girls have undergone FGM/C. More than $50 \%$ of the 200 million girls and women live in three high-prevalence countries: Indonesia, Egypt, and Ethiopia. Given the increase in population growth, recent estimates show that the number of girls and women subject to $\mathrm{FGM} / \mathrm{C}$ will continue to rise in the coming years unless sufficient efforts are undertaken to encourage abandonment of the practicepractise. A descriptive analysis of changes in $\mathrm{FGM} / \mathrm{C}$ prevalence over time in Ethiopia shows that the percentage of women aged 15-49 years who report undergoing $\mathrm{FGM} / \mathrm{C}$ has been declining. Despite the decline, the $\mathrm{FGM} / \mathrm{C}$ prevalence is still high at $65 \%$ with new incidences of girls being cut frequently reported. Various interventions have been implemented in Ethiopia for decades with varying success - the prevalence varies across regions and cultures in the country. Notwithstanding the importance of social norms in driving FGM/C, we are not aware of studies that have undertaken an in-depth analysis of shifts in social norms and practises associated with $\mathrm{FGM} / \mathrm{C}$ in Ethiopia. This study, therefore, explored changes in social norms and practises associated with FGM/C in two "hot spot" regions: Somali-a region with the highest FGM/C prevalence; and Oromia - the largest region in the country with a history of practising FGM/C.

\section{Methods}

This inquiry was a cross-sectional qualitative study conducted in two administrative zones of Ethiopia: West Arsi (Oromia region) and Fafan (Somali region). In-depth interviews and focus group discussions were used to collect data.

\section{Results}

Government agencies and local NGOs are the major actors engaged in the implementation of FGM/C interventions. Programme implementers used various approaches to inform community members of the consequences of practising FGM/C and encourage them to abandon the practise. The main intervention approaches were community conversation, legal intervention, religious and health-risks approaches. Programme implementers faced various challenges in their quest to end $\mathrm{FGM} / \mathrm{C}$ in the two study settings. These included: resistance from community members, lack of sustainability of anti-FGM/C interventions, poor selection of change agents, reluctance of religious leaders to fully support abandonment efforts, exclusion of boys in the implementation of interventions, and legal restrictions. Interventions implemented in the two study sites have had varied levels of influence on community values and deliberations. Changes in norms and practises observed in the two study settings varied significantly.

West Arsi embraced an increasing awareness of and community participation in enacting bylaws and enforcing the anti-FGM/C law. Community values and norms related to marriageability, purity, respect, and other perceived advantages of $\mathrm{FGM} / \mathrm{C}$ were challenged. Changes in norms were followed by abandonment of the practice as evidenced by an increase in the number of girls abandoning $\mathrm{FGM} / \mathrm{C}$, uncut girls were getting married, social pressure on uncut girls and their parents was declining, and uncut girls were considered to be modern and educated. Despite changes in norms and practises, girls who decided to remain uncut were still subjected to pressure from mothers-in-law to undergo the cut during marriage. A newly married uncut woman may decide to conform to the norm (undergo FGM/C) if she thinks that her in-laws believe that she ought to (normative expectation) or that other women surrounding her marital home conform to the norm (empirical expectation). 
The situation in Fafan was different. Shifts related to FGM/C were mainly limited to awareness of the health consequences of $F G M / C$. Significant alterations of $F G M / C$ norms and practices were not observed. The association between FGM/C and marriageability, purity, virginity, and respect remained very strong. Abandoning FGM/C in Fafan involved a high social risk as sanctions against uncut girls/women were severe. Abandonment of FGM/C was difficult as parents believed that other parents were cutting their daughters (empirical expectation); that community members expected every girl to undergo FGM/C (normative expectation); and that uncut girls would face negative sanctions including social exclusion. Despite slight changes towards the less severe type of FGM/C (Sunna cut) in urban areas, infibulation was still highly cherished and widely practised.

\section{Implications for programmes and research}

\section{Programmatic implications}

- An integrative approach in programme implementation, with a clear focus on engaging community members in values deliberation, especially in West Arsi is likely to facilitate community wide $\mathrm{FGM} / \mathrm{C}$ abandonment.

- Informed selection of change agents and building their capacity to facilitate normative behaviour change will be key in spearheading implementation of interventions to end FGM/C. Since health extension workers and religious leaders are highly valued and listened to in the community, their involvement in programme implementation will be crucial in accelerating abandonment of the practice.

- Given that findings from the two sites present differing scenarios, there is no single set of interventions that will work in all settings. There is a need for tailored programming that is sensitive to the local realities.

\section{Research implications}

- A quantitative survey measuring communities' readiness for FGM/C abandonment is needed as a follow-up inquiry in both the West Arsi and Fafan administrative zones.

- Expansion in the application of vignettes and indirect questioning methods for sensitive issues such as $\mathrm{FGM} / \mathrm{C}$ in contexts where social desirability is high. 


\section{Introduction}

\section{Background}

As defined by the World Health Organization (WHO), FGM/C refers to all procedures involving partial or total removal of the external female genitalia or injury to the female genital organs for nonmedical reasons. This includes practises such as cutting, piercing, removing, and sewing the external parts of the female genitalia. FGM/C is classified into the following four broad types: Type I (clitoridectomy)—involves partial or total removal of the clitoris; Type II (excision)—entails partial or total removal of the clitoris and the labia minora, with or without excision of the labia majora; Type III (infibulation) -involves narrowing of the vaginal opening through the creation of a covering seal; and Type IV (other forms of FGM/C) -includes all other harmful procedures to the female genitalia for nonmedical purposes (WHO 2014). The practice is considered a violation of the rights of girls and women (WHO 2014). Specifically, FGM/C is regarded as a violation of women's rights to bodily/physical integrity, a violation of God-given integrity of girls' and women's bodies in some African cultures (Mehari 2016, Abusharaf 1995, Ramos and Boyle 2000, Amado 2004), and therefore negatively affects the well-being of girls and women. Health implications of the practice include severe bleeding, infections, infertility, risk of complications during childbirth, and an increased risk of newborn deaths. The negative implications of Type III FGM/C (infibulation) are more severe as it involves stitching and opening (de-infibulation) during marriage and childbirth (WHO 2014).

Globally, more than 200 million women and girls have undergone FGM/C. More than $50 \%$ of the 200 million girls and women live in three high-prevalence countries: Indonesia, Egypt, and Ethiopia. Recent estimates show that the number of girls and women subject to FGM/C will increase in the coming 15 years as current achievements are not sufficient to keep up with an increasing population growth (UNICEF 2016). The number of girls at risk of FGM/C every year is around 3.6 million (Shell-Duncan and Feldman-Jacobs 2016). FGM/C practices are highly concentrated in the African continent stretching from the tip of western Africa (Senegal, Gambia and Liberia); and extending to North Africa (Egypt), the Horn of Africa (Djibouti and Somalia), and other parts of Eastern Africa (Kenya, Uganda, Tanzania, and Ethiopia). According to the 2016 UNICEF report, the prevalence of FGM/C among women aged 15-49 years varied across African countries. Out of the top 10 African counties with high prevalence, three countries with more than $90 \% \mathrm{FGM} / \mathrm{C}$ prevalence are Somalia (98\%), Guinea (97\%), and Djibouti (93\%). Ethiopia is ranked eleventh with a prevalence of $65 \%$ (UNICEF 2016).

Campaigns against harmful traditional practices have been carried out in Ethiopia in the last two decades by a small number of organisations together with the Ministry of Health. The number of organisations working on harmful traditional practices (HTP), including FGM/C, uvula cutting, milk teeth extraction, and early marriage, increased to more than 80 in the 1990s. This number radically declined after the Proclamation for the Registration and Regulation of Charities and Societies was endorsed by the Ethiopian government in 2009 (Hagmann and Abbink 2011). The law prohibited international organisations from conducting human rights work. Domestic NGOs obtaining more than 10 per cent of their annual budget from foreign sources were also prohibited from implementing rights-based programmes (FDRE 2009). Prior to the Charities and Societies Law (CSL), the percentage contribution of NGOs working on HTPs by region was: Amhara $(24 \%)$, Oromia (12\%), SNNPR (12\%), Addis Ababa (11\%), Tigray (11\%), Afar (10\%), Harari (9\%), Somali (4\%), Gambella (3\%), and Benishangul-Gumuz (4\%) (28TooMany 2013). The Ethiopian government has in the recent past shown a commitment towards elimination of $F G M / C$. It developed a National Strategy of Harmful Tradition Practices and criminalised FGM/C in 2005 (CSA and ICF 2016). FGM/C and child marriage have been identified as the most prevalent HTPs 
and prioritised for elimination in the National Strategy and Action Plan on HTP against women and children (Pankhurst 2014). Within this policy and legal framework, governmental and nongovernmental organisations have been implementing programmes to accelerate the abandonment of $\mathrm{FGM} / \mathrm{C}$.

Efforts by the government and NGOs working towards FGM/C abandonment has led to a decline in $\mathrm{FGM} / \mathrm{C}$ prevalence over time. However, the decline is not sufficient as the national prevalence is still high (65\%), new incidences of girls being cut are frequently reported, and there is great variability across communities and regions within the country. It is therefore critical to find out what changes have occurred in communities that have traditionally practised FGM/C. The various waves of the Ethiopia Demographic and Health Surveys (EDHS) confirm that there is a change in prevalence and perhaps a change in norms, but we are not aware of studies that have conducted an in-depth analysis of changes in practises and social norms associated with FGM/C in Ethiopia. There is therefore a need for a more nuanced understanding of how and why these changes are occurring - particularly in settings where the change in prevalence has been rapid, and in those where the change has been subtle.

\section{Evidence of abandonment, changes, and persistence in Ethiopia}

The prevalence of $\mathrm{FGM} / \mathrm{C}$ in Ethiopia varies considerably across regions and cultures (Figure 1). According to the 2016 EDHS, the three regions with the highest prevalence are Somali (99\%), Afar (91\%), and Harari (82\%). In addition to exhibiting a high prevalence of $\mathrm{FGM} / \mathrm{C}$, these regions share the following similarities: Somali and Afar are in the eastern part of the country, all three regions are predominantly inhabited by pastoral communities, the overwhelming majority of their populations are adherents of Islam, and infibulation is widely practised in these regions. The prevalence of $\mathrm{FGM} / \mathrm{C}$ in the second category of regions falls between $62 \%$ and $76 \%$. The highest prevalence under this category $(76 \%)$ is observed in Oromia, the largest and most populous region in Ethiopia, followed by Benishangul-Gumuz (63\%), Amhara (62\%), and Southern Nations, Nationalities and Peoples (SNNP) regional states (62\%). The prevalence of the practise in Addis Ababa (54\%), the country's capital, and Dire Dawa (79\%), the biggest city in eastern Ethiopia, is also high. The two regions with relatively low FGM/C prevalence are Tigray (24\%) and Gambella (33\%) (CSA and ICF 2016).

Figure 1. Changes in FGM/C prevalence across regions of Ethiopia (EDHS 2000, 2005, and 2016)

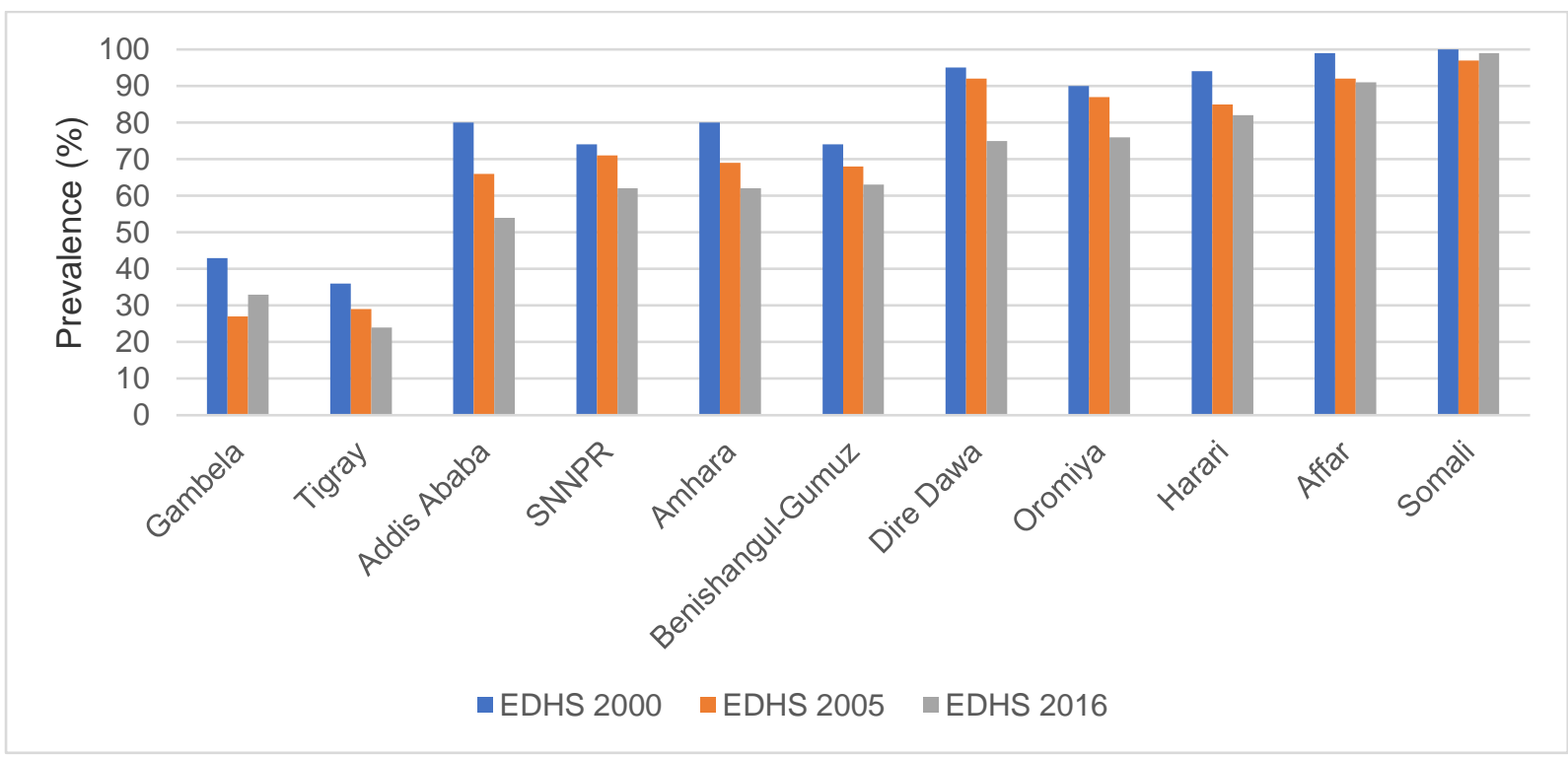


Changes in FGM/C prevalence also vary across different regional states in Ethiopia. Figure 1 portrays changes in prevalence rates for all types of FGM/C from 2000 to 2016 in nine regional states and two city administrations (Addis Ababa and Dire Dawa) based on the EDHS findings. The three areas exhibiting the highest decline were Addis Ababa (from 79.9 to 54\%), Dire Dawa (95.1\% to $75.3 \%$ ), and Amhara (79.7\% to $61.7 \%$ ) whereas Somali (99.7\% to $98.5 \%$ ) and Afar (98.6\% to $91.2 \%$ ) showed a slight decline from 2000 to 2016 . Although Tigray (from $35.7 \%$ to $24.2 \%$ ) and Gambela (42.9\% to $33.3 \%$ ) showed a moderate level of decline in FGM/C prevalence, they are the two regions with the lowest prevalence of the practise. Changes in prevalence in the two regions (Oromia and Somali) during the specified time varied considerably: prevalence declined in Oromia from $89.8 \%$ to $75.6 \%$ while it was more stable in the Somali region (prevalence of the practise declined by $1.2 \%$ from 2000 to 2016 ).

The above description of changes in FGM/C prevalence is based on regional administrations and hence it does not specifically portray changes along ethnic lines. Data on ethnic groups can give insights on some hotspots in SNNP Region which is the home of more than 45 ethnic groups. For example, FGM/C prevalence in SNNP Region is $62 \%$ which is much lower than the prevalence among the Sidama (88\%)—one of the ethnic groups in the same region. For the other eight regions (e.g., Somali, Oromia, and Afar) the difference between regional and ethnic prevalence was minimal. The regional prevalence in Somali $(98.5 \%)$, Oromia (76\%), and Afar (91\%) is not much different from the overall prevalence among ethnic Somali (98.5\%), Oromo (77\%), and Afar (98\%) (CSA and ICF 2016).

The distribution of different types of FGM/C in Ethiopia also varies across regions and cultures. Clitoridectomy, excision, and infibulation are the most commonly practised types of $F G M / C$ in Ethiopia (Spencer 2012). Notably, different data sources present different figures on the distribution of FGM/C by types in the country. According to the 2016 EDHS, $73 \%$ of cut women aged 15-49 years were cut and had flesh removed, $7 \%$ were sewn closed, and $3 \%$ were cut but no flesh was removed. According to 28TooMany, the percentage of women who have undergone clitoridectomy and excision was $92 \%$ whereas $8 \%$ have undergone infibulation (28TooMany 2013). A combination of clitoridectomy and excision is extensively practised in some regions in varying degrees: 92\% in Tigray, 63\% in Amhara, and 54\% in SNNP (Spencer 2012).

A cohort analysis of changes in FGM/C prevalence by age showed that FGM/C prevalence among girls/women aged $15-19$ years (47\%) is lower than the prevalence for the older cohort of women aged 35-49 years (75\%) (Figure 2). Overall, the current prevalence rate in Ethiopia is still high compared to other African countries such as Nigeria (25\%), Senegal (24\%), and Kenya (21\%) (MFED and MWCYA 2013). 
Figure 2. Prevalence of FGM/C by age (EDHS 2016)

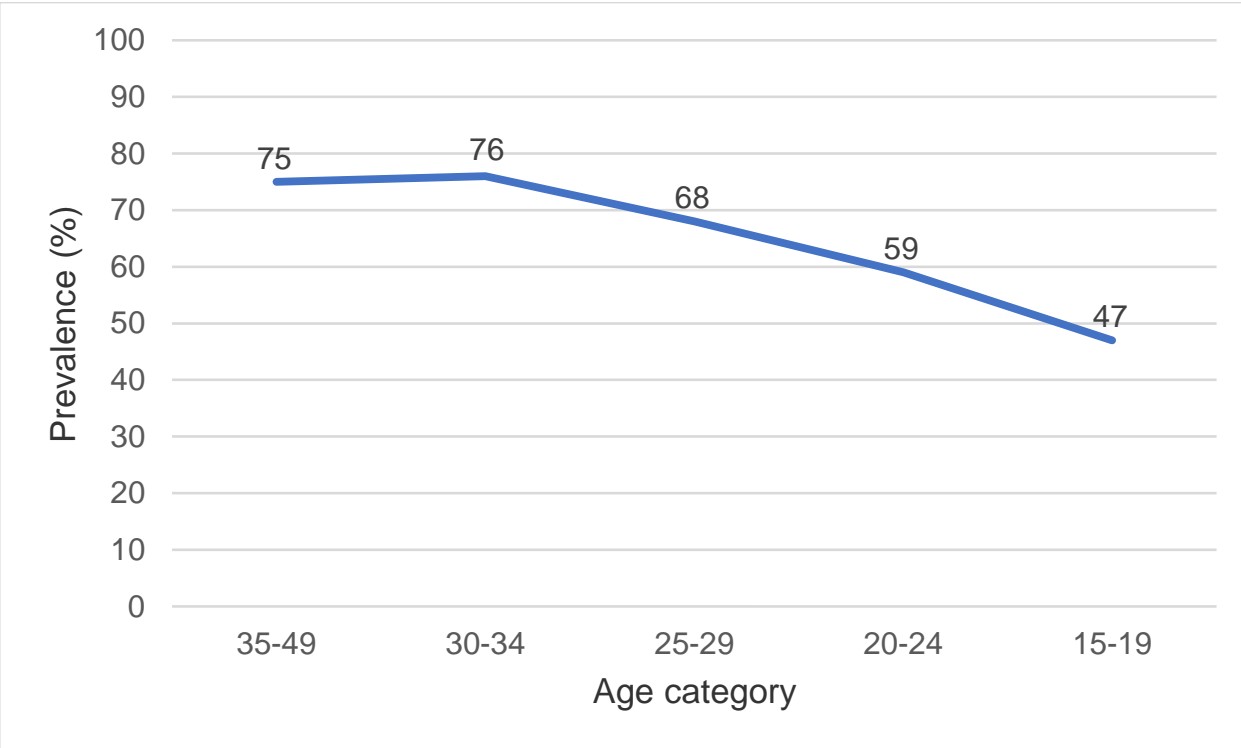

As shown in Figure 3, FGM/C prevalence among girls aged $0-14$ years is consistently lower than that of women aged 15-49 years. Importantly, a greater percentage point decline in prevalence was observed among girls younger than 15 years-from $52.0 \%$ in 2000 to $37.7 \%$ in 2005 and to $15.7 \%$ in 2016.

Figure 3. Changes in FGM/C prevalence in 15-49 and 0-14 age categories (EDHS 2000, 2005, and 2016)

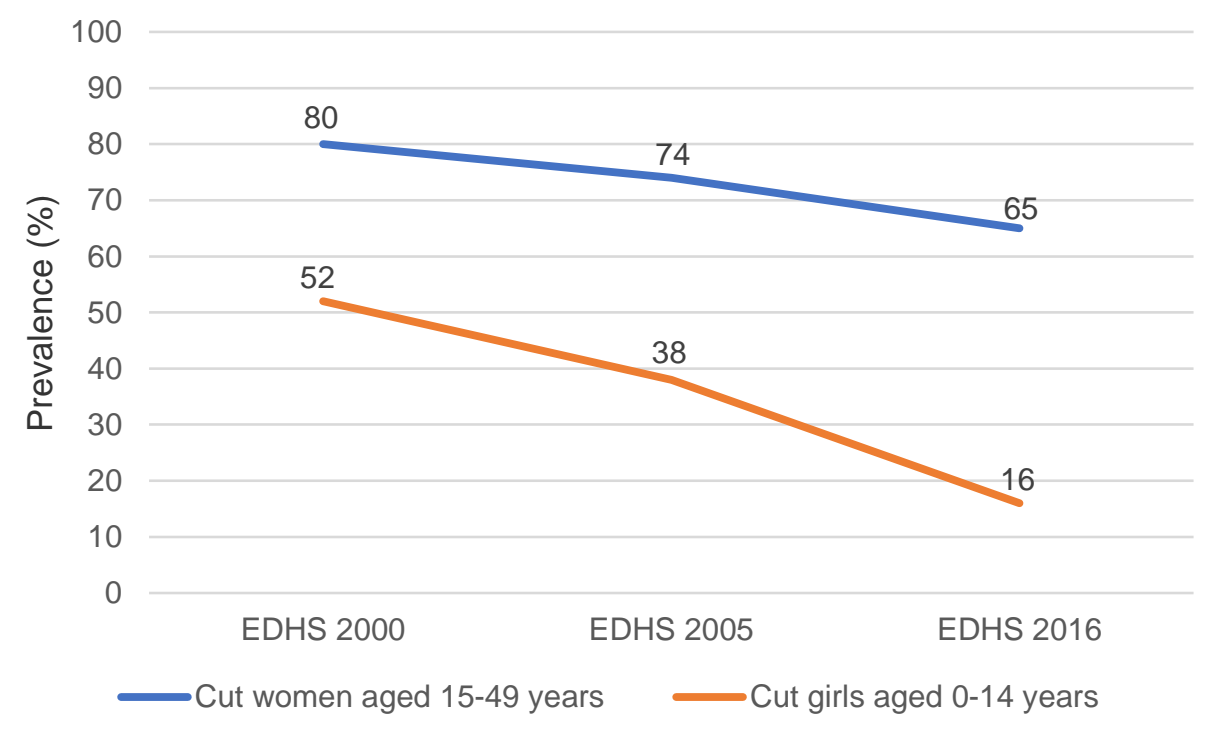

Estimates at the national level show some changes in FGM/C norms and practices. In the 2005 EDHS, for example, $31 \%$ of women and girls aged 15-49 years who had heard of FGM/C stated that the practice should continue (CSA and ORC Macro 2006). After a decade, the percentage of women and girls supporting the continuation of the practice declined to $18 \%$ (CSA and ICF 2016). According to a study on Somali women in Jigjiga in $2013,50 \%$ of the respondents supported the abandonment of $\mathrm{FGM} / \mathrm{C}$ while $36 \%$ supported the continuation of the practice. With regard to the type of the practice, $83 \%$ of women preferred less severe cutting for their daughters (Hussien, Adem, and Mohammed 2013). The growing support for less severe cutting is partly because some people accept that infibulation could harm the well-being of women (Pankhurst 2014). 
Religion is considered as one of FGM/C's main drivers with sources indicating that people tend to associate FGM/C with religious obligations. For example, the 2016 EDHS report showed that $24 \%$ and $17 \%$ of women and men, respectively, who reported that they had heard of female circumcision believed that the practice was a religious requirement (CSA and ICF 2016). Nonetheless, new developments are emerging as religious leaders reject the religious basis of FGM/C. According to a 2015 Norwegian Church Aid publication, major faith-based organisations (FBOs) in Ethiopia have been engaged in deliberations and theological reflection on FGM/C (NCA 2015). The following Faith Based Organisations (FBO) have denounced the religious basis of the practice and made national declarations against FGM/C: The Evangelical Churches Fellowship of Ethiopia (ECFE) in 2010, the Ethiopian Orthodox Tewahedo Church (EOTC) in 2011, and the Ethiopian Catholic Church in 2013. The Ethiopian Islamic Affairs Supreme Council (EIASC) held a national consultation on FGM/C with grand Ulammas (scholars) and top religious leaders in 2010 (NCA 2015). In Afar region, the Islamic Affairs Supreme Council declared that Islam does not support FGM/C (Dagne 2009).

The other shift relates to changes from more severe to less severe forms of FGM/C. The 2016 EDHS report showed that among women who had reported having undergone the cut, the most common type of $\mathrm{FGM} / \mathrm{C}$ involved cutting and removal of flesh (73\%). Seven per cent of women reported having undergone infibulation-their genital area had been sewn closed (CSA and ICF 2016). Shifts to less severe forms of FGM/C (referred to by some as the Sunna cut) have been observed in regions where infibulation is widely practised (Somali, Afar and Harari) (Spadacini and Nichols 1998). The shift from infibulation to a less severe form of $F G M / C$ is regarded as resistance to a complete abandonment of the practice (NCA 2011). In addition to the changes noted above, there are emerging challenges that hinder FGM/C abandonment in Ethiopia. The first one is underreporting of the practice which has implications for policy and interventions. The main driver of underreporting is the fact that $\mathrm{FGM} / \mathrm{C}$ is illegal in Ethiopia. The second challenge is resistance to the abandonment of $\mathrm{FGM} / \mathrm{C}$ by the younger generation. Findings of a study conducted in the Oromia region in 2013 show that resistance to ending FGM/C sometimes comes from girls who may organise their own circumcision and take responsibility to protect their families and traditional practitioners from legal sanction (Boyden, Pankhurst, and Tafere 2013). Evidence also shows a widespread practise of $\mathrm{FGM} / \mathrm{C}$ in secret. In some communities, FGM/C is performed at night to keep the practice hidden and families send their daughters to distant and remote areas to undergo FGM/C (Dagne 2009).

\section{Study aim and objectives}

The study aimed to conduct an in-depth analysis exploring changes in norms and practises related to $\mathrm{FGM} / \mathrm{C}$ in two study districts located in the West Arsi zone (Oromia regional state-quantitative data indicate a declining trend in $\mathrm{FGM} / \mathrm{C}$ prevalence) and the Fafan zone (Somali regional statequantitative data indicate no decline in FGM/C prevalence) in Ethiopia. The specific objectives of the study were:

(i) To explore the influence of $F G M / C$ interventions on community deliberations related to FGM/C norms and practises in the West Arsi and Fafan zones;

(ii) To trace changes in norms and practises associated with FGM/C in the West Arsi and Fafan zones; and

(iii) To assess challenges (social, cultural, or political) experienced by entities trying to change pro-FGM/C norms and practises. 


\section{Theoretical underpinnings}

\section{Tracing changes in FGM/C norms through the social norms perspective}

This study was informed by the social norms theory. Social norms theory has been used to explore health issues (Berkowitz 2004) such as understanding the drivers of harmful practises like early girl/child marriage (Bicchieri, Jiang, and Lindemans 2014) and FGM/C (Mackie et al. 2015). The theory has been helpful in the measurement of changes in beliefs and actions that sustain harmful practises such as early marriage and FGM/C (Mackie et al. 2015). It has therefore been argued that social norms theory should inform interventions aimed at ending harmful practises that are sustained by social norms (Bicchieri, Jiang, and Lindemans 2014). Mackie et al. (2015) argue that human behaviour is influenced by three types of beliefs: beliefs about one's self or perceived behavioural control over an action, belief about the nonsocial environment, and beliefs about the social environment. One's belief about the social environment includes beliefs about what others do (empirical expectations), and beliefs about what others think we ought to do (normative expectations), and social approval/disapproval that maintain social norms. This means that people feel social pressure to conform to social norms. Development programmes have tended to focus on measuring changes in one's beliefs and self-efficacy while overlooking beliefs about the social environment, which are gateways to the understanding of social norms (Mackie et al. 2015).

Human actions vary from highly independent (actions not influenced by beliefs and actions of other people), to the one-way dependent (the diffusion of new technology from one person to another), to the highly interdependent (actions influenced by interdependent social expectations). Interventions aimed at changing individuals' independent behaviour through the provision of information and services such as education, though of great significance, may not be effective to address harmful interdependent behaviours guided by social norms. Focusing on beliefs and actions of most of the members within the reference group is essential to accelerate the abandonment of highly interdependent harmful actions (e.g., practising FGM/C). The social norms theory therefore enhances the understanding of interdependent actions and informs policies and programmes aimed at ending harmful practises such as FGM/C (Mackie et al. 2015).

One of the challenges of measuring changes in ending harmful practises has been the absence of measurement tools (Bicchieri, Jiang, and Lindemans 2014; Mackie et al. 2015). Beliefs and actions of members of a given community (reference group) could be informed by social expectations or nonsocial beliefs. Identifying the distinction between social expectations and nonsocial beliefs is indispensable for measuring changes in harmful social norms and practises. Social expectations include normative expectations and empirical expectations. For example, in communities where $\mathrm{FGM} / \mathrm{C}$ is a social norm, parents' normative expectations may include disapproval of abandoning $\mathrm{FGM} / \mathrm{C}$ and negative sanctions against uncut girls (e.g., social exclusion). Parents also care about what others do (empirical expectation). Parents may prefer to comply with social norms if they believe that most of the parents in their community let their daughters undergo FGM/C. In addition to social expectations, beliefs and actions of parents could be influenced by nonsocial aspects such as personal opinions including false beliefs such as "health consequences of FGM/C are caused by bad spirits" and factual beliefs such as the marriageability of an uncut girl will be compromised. Hence, differentiating social norms from other norms (e.g., moral norms, personal norms, and legal norms) is important to designing programmes and evaluating and monitoring changes in ending harmful practises.

In addition to understanding the distinction between the social environment and the nonsocial environment, Mackie et al. (2015) have proposed the significance of identifying: 1) whether the reference group has changed, 2) whether the old norm is less approved of and less typical in the reference group over time, and 3) whether the new norm is more approved of and more typical in 
the reference group over time. In general, in the process of measuring changes in social norms, there is a need to focus on one's belief about others (social expectations), identifying the reference group, and the anticipated reactions of others to compliance or noncompliance with the social norm.

Programmes aimed at accelerating the abandonment of FGM/C have been implemented across regions of Ethiopia. Anti-FGM/C programmes in Ethiopia have been employing different methods. Though the decline of the prevalence of FGM/C has been reported at a national level, there is a paucity regarding within a country changes in norms and practises associated with $F G M / C$, especially looking at communities that have experienced a decline in prevalence and those that have not.

\section{Methods}

\section{Study design}

A cross-sectional study design was employed, using qualitative methods. The study involved indepth interviews (IDIs) and focus group discussions (FGDS). IDIs were conducted to assess individual experiences (including challenges towards abandonment and the possible impacts of interventions) and beliefs and attitudes related to FGM/C; while FGDs aimed to explore changes in norms and practises related to $\mathrm{FGM} / \mathrm{C}$ at a community level.

\section{Study sites}

Ethiopia is a land-locked country located in the Horn of Africa. It shares boundaries with six countries in eastern and northeastern Africa: Sudan and South Sudan in the west, Eritrea in the north, Djibouti and Somalia in the east, and Kenya in the south. As compared to the six neighbouring countries, Ethiopia is the most populous nation with a 2017 projected population of $94,351,001$ (46,986,992 female, 47,364,009 male) (CSA 2013). After the downfall of the Derg regime in 1991, a "socialist government" led by military officials adopted an ethnic-based federal system. The political map of the country is divided into nine regional states based on ethnic lines and two autonomous cities: Addis Ababa and Dire Dawa (Figure 4). 
Figure 4. Administrative map of Ethiopia (Source: http://ontheworldmap.com)

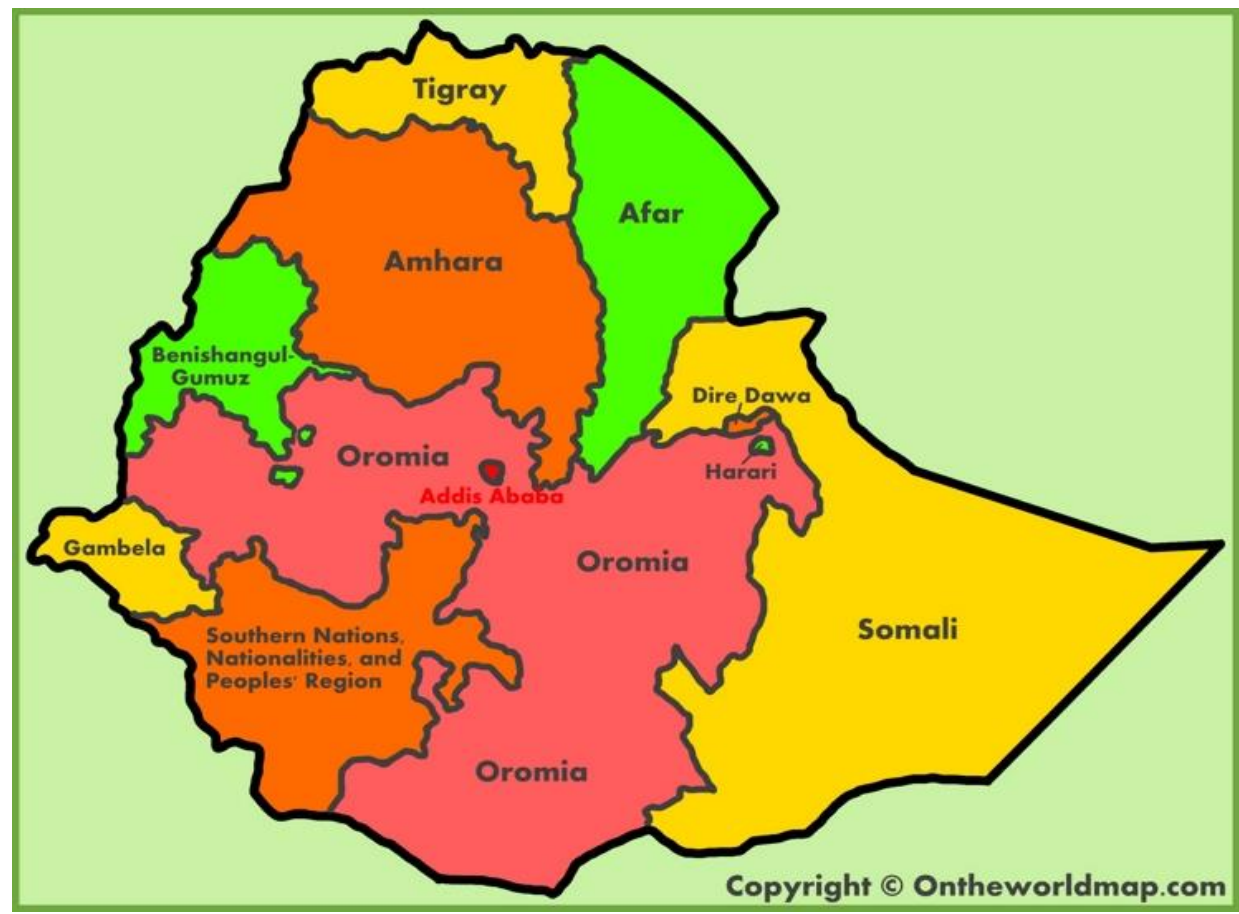

\section{Study regions and zones}

Ethiopia is a large country divided into regional states. The two regions selected for this study are highlighted in Figure 5. Among regions of Ethiopia, the Somali region exhibits the largest prevalence of $\mathrm{FGM} / \mathrm{C}(98 \%)$ (CSA and ICF, 2016) with a remarkable stability in terms of prevalence and reportedly dramatic shifts from infibulation to less severe forms of FGM/C. Therefore, this study explored changes and continuities in FGM/C norms and practises in the two regions with diverse characteristics-Somali region with a more stable and very high FGM/C prevalence and Oromia region with a comparatively lower prevalence and some level of changes in prevalence.

As the regional state structure is too far from districts and local communities, further narrowing down of the study areas was imperative. Based on a desk review and consultative meetings with stakeholders, two administrative zones-the West Arsi Zone in Oromia region, and the Fafan Zone in Somali region were selected as the specific study sites. In addition to exhibiting high FGM/C prevalence, the zones offered an opportunity to explore changes in FGM/C norms and practises in different socio-cultural settings. Most of the population in the Fafan zone are nomadic pastoral communities while a majority of those living in the West Arsi zone practise sedentary agricultural farming. 
Figure 5. Locations of study areas: Fafan and West Arsi zones (Source:

(https://upload.wikimedia.org/wikipedia/commons/thumb/8/80/Map of zones of Ethiopia.svg/35 Opx-Map of zones of Ethiopia.svg.png)

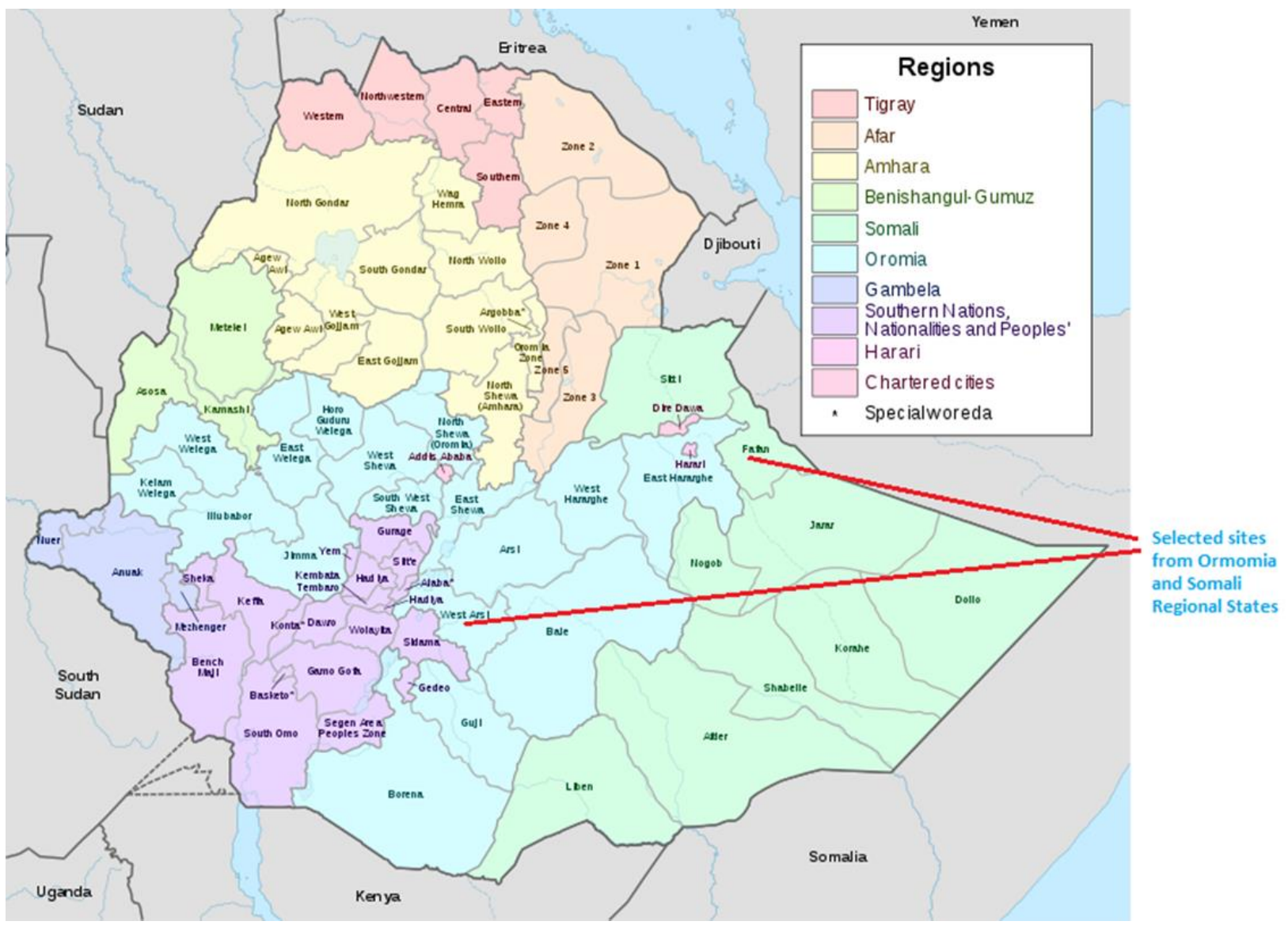

\section{Fafan zone, Somali region}

The population of the Fafan zone (previously named Jigjiga zone) was estimated to be more than one million. The Fafan zone is divided into seven districts: Ajersagoro, Awbare, Kabribayan, Harshin, Gursum, Jigjiga, and Babille. Fafan is selected as a study zone for two reasons. First, it is inhabited by people coming from different parts of the Somali region. Second, the geographic location of the zone is suitable for gathering evidence from districts situated around Jigjiga, the headquarters of the Somali region. Security issues were also considered in the selection processthe Fafan zone seemed more stable as it is the headquarters of the regional government.

\section{West Arsi zone, Oromia region}

The West Arsi zone is one of the 17 administrative zones in Oromia. The total population in the zone was projected to be approximately $2,591,152(1,280,051$ male and $1,311,101$ female) (CSA 2013). The West Arsi zone is divided into 15 districts and more than 200 kebeles. The zone is predominantly inhabited by the Arsi Oromo. Most of the people in the zone are adherents of Islam. The dominant livelihood activities in the zone are sedentary agriculture followed by agropastoralism. In addition to its economic benefits, cattle ownership is associated with prestige. Cattle serve non-economic purposes: they are transferred as dowry during marriage and offered as compensation in resolving conflicts (Hebo 2014). West Arsi was selected as a study zone for the following reasons: 1) FGM/C has been a deep-rooted tradition among the Arsi Oromo; and 2) some of the districts are reportedly exhibiting dynamic situations (changes and continuities) because of FGM/C interventions. Conducting FGM/C research in West Arsi provided researchers 
with opportunities to explore changes in norms and practises, especially on how norms are negotiated and contested.

\section{Participants}

Table 1 summarises the data-collection activities and the number of study participants. Forty-nine study participants were interviewed from six categories: community gatekeepers including community and religious leaders (10), fathers of girls (10), mothers of girls (10), girls aged 15-17 (10), health extension workers (4), and programme implementers (5). In addition to in-depth interviews, eight FGDs (four in West Arsi and four in Fafan) were conducted to collect additional data. FGDs involving young women and men (18-35-year-olds) and older women and men ( $\geq 36$ year-olds) were conducted to explore participants' views on FGM/C norms and practises.

\section{Table 1. Number of study participants}

\begin{tabular}{|l|c|c|c|}
\hline Data-gathering activities & Fafan Zone & West Arsi Zone & Both sites \\
\hline In-depth interviews & 2 & 1 & 3 \\
\hline Village elders & 1 & 1 & 2 \\
\hline Women's group leaders & 1 & & 1 \\
\hline Religious leaders & 1 & 1 & 2 \\
\hline Government officials & \multicolumn{2}{|l|}{} \\
\hline Teachers & 2 & 2 & 2 \\
\hline Healthcare workers & 2 & 2 & 4 \\
\hline Programme implementers & 5 & 5 & 10 \\
\hline Mothers of girls aged 5-20 & 5 & 5 & 10 \\
\hline Fathers of girls aged 5-20 & 5 & 5 & 10 \\
\hline Girls in the community (15-17) & \multicolumn{3}{|c|}{} \\
\hline Focus group discussions & 1 & 1 & 2 \\
\hline Younger women (18-35) & 1 & 1 & 2 \\
\hline Older women (40+) & 1 & 1 & 2 \\
\hline Younger men (18-35) & 1 & 1 & \\
\hline Older men (40+) & \multicolumn{2}{|l}{} \\
\hline
\end{tabular}

\section{Instruments}

The FGDs were guided by indirect story-based questions (vignettes) and direct questions informed by factorial focus group design. The development of IDI and FGD guides was informed by tools used by Shell-Duncan and colleagues (2011) in a study on dynamics of change in the practice of female genital cutting in Senegambia. Indirect story-based questions were developed with input from experts from the specific communities. All interviews and discussions were recorded using digital voice recorders. Data-collection tools were pretested and adapted to the local context before the beginning of the actual data collection process.

\section{Procedures}

For IDIs and FGDs, study participants were recruited from local communities, government offices at district levels, and local NGOs implementing FGM/C programmes in the two study sites. Study participants were purposively selected with the support of health extension workers, programme implementers, and representatives of district women's affairs offices. Snowball sampling was also used to find key informants such as community and religious leaders. IDIs and FGDs were conducted in April and early May in 2019.

\section{Data analysis}

Field data in the form of audio recordings of IDIs and FGDs were transcribed and coded using NVivo version 12 software. IDIs and FGDs conducted in local languages were directly translated into English. The data-analysis activities were divided into two phases: first, using an inductive 
analysis approach, the data-analysis team reviewed text data from interviews and identified themes and patterns corresponding to themes and constructs that had been entered into the database, which were used in writing mini-reports. The activities of the first phase played an important role in reducing the data to a manageable size. The second phase of the data analysis activities was accomplished by the Principal Investigator (PI). The PI reviewed output from the data-analysis team which involved selecting key quotes exemplifying a certain theme and merging or expanding themes while developing the narrative.

Data analysis for FGDs began with the premise that "coding is analysis" (Miles and Huberman 1994), and we therefore used an iterative process that involved the following sequential activities: rounds of coding text to identify themes or categories, writing memos to explore themes and identify relations among themes or categories, and linking themes to building analytical models (Bernard 2011; Creswell 2007). This was followed by developing a summary document for each FGD, identifying the major themes raised. For FGDs guided by the factorial design, we grouped the major themes along the lines of perceived advantages or disadvantages of $F G M / C$ - this was to assist in assessing changes in norms and practises related to FGM/C. Thereafter, notations recorded the emphasis placed on each theme (ranging from a passing remark to a topic that participants deeply explored), as well as the degree of consensus, debate, or disagreement that came about during the discussion. This process served as an analytic approach to discerning the degree to which normative statements and positive or negative associations were shared among participants, debated, or contested during the discussion. Adopting the recommendation of Knodel (1993), we used a team approach to creating data summaries and identifying themes to improve reliability of the data analysis. Team members engaged in the data analysis identified topics and patterns individually, and then met to discuss interpretation of emerging themes and identify direct quotes from the transcripts that illustrated a concept or theme (Bernard 2011).

The summaries for each FGD were used to create an "overview grid" adopting Knodel's methods (1993) elaborated by Shell-Duncan et al. (2019). The overview grid allows comparisons along the lines of break characteristics (younger vs. older, men vs. women) and location of residence (West Arsi vs. Fafan). Basic themes were grouped into main themes, and a summary matrix was created for each main theme. This matrix recorded variations in themes, direction, and degree of consensus along break characteristics. Analytic memos were created to describe themes that emerged through the analysis, exploring patterns and overarching themes that formed the basis for the interpretation of the results.

\section{Ethical considerations}

Ethical approval for the study was obtained from the Population Council's Institutional Review Board (Protocol 875) and Ethiopian Society of Sociologists, Social Workers, and Anthropologists' Institutional Review Board (ESSSWA/005/2018). Official approval letters were received in January 2019. Written informed consent was obtained from study participants before conducting interviews and group discussions. Potential participants were given an opportunity to decide whether to read, or have the research assistant read for them, the informed consent document and to indicate their willingness to be interviewed by signing the form. Parent/guardian consent was obtained prior to obtaining the assent of young girls aged below 18 years. The following procedures were followed to assist study participants who could not read and write: 1) data collector read the content of the informed consent for them; and 2) study participants affirmed their consent to participate in the study by using their thumbprints as a sign of consent.

\section{Results}

This section outlines the major findings of the study. It is organised around the three study objectives. First, we present findings exploring the influence of FGM/C interventions on community 
deliberations related to $\mathrm{FGM} / \mathrm{C}$; we then present findings tracing changes in norms and practises associated with $\mathrm{FGM} / \mathrm{C}$; and last we present the challenges experienced by entities trying to encourage $\mathrm{FGM} / \mathrm{C}$ abandonment.

\section{FGM/C interventions: Actors and achievements}

The first objective of this study was to explore the influence of FGM/C interventions on community deliberations related to FGM/C norms and practises in the two study settings. This section outlines the main findings related to FGM/C interventions focusing on actors and some of the achievements of implemented interventions.

\section{Actors and focus areas}

Various actors were engaged in FGM/C interventions in the two study administrative zones. The major actors were government institutions and offices (e.g., Women Affairs Offices, Health bureaus, healthcare institutions, and schools), women's associations, local NGOs, and international organisations. Religious leaders, community leaders, health extension workers, and teachers were also among change agents.

The government was the leading actor in implementing FGM/C programmes in the two study areas. This was because the Charities and Societies Law barred local NGOs from implementing rightsbased programmes if they generated more than $10 \%$ of their annual budget from abroad, leaving government agencies as the primary actors with the freedom to implement anti-FGM/C programmes. Government offices such as the Ministry of Women, Children, and Youth Affairs and women's affairs bureaus and offices from the regional to the district and grassroots levels are actively engaged in programme implementations to encourage $F G M / C$ abandonment. The government has also been implementing various FGM/C programmes through Health Bureaus and health care institutions across districts. The following quotations illustrate the role of the government in this regard.

"The government has already banned this thing [FGM/C], and every neighbourhood is aware of the bad sides of this thing. So, those who do not get circumcised do not face any problem.... Thanks to the government, locals abandoning circumcision do not fear social pressure of the society."

(Religious leader, IDI, West Arsi)

"In our kebele we have interventions implemented by government agencies on Gudnika Faronika [infibulation]...Gudnika Faronika is a traditional practice that has affected many girls and women around the kebele. The practice has recently received much attention from the government, and nongovernmental organisations."

Healthcare worker, IDI, Fafan)

The Charities and Societies Law excluded international organisations from direct involvement in the implementation of $\mathrm{FGM} / \mathrm{C}$ programmes. As a result, their role was limited to providing financial and technical support to local NGOs and government agencies implementing FGM/C programmes. Local NGOs played an important role in implementing FGM/C programmes in both study zones and districts. However, the number of local NGOs working on FGM/C is low and their activities are constrained by the CSL. For example, the number of local NGOs implementing FGM/C programmes in West Arsi zone were only two whereas one local NGO was engaged in intervention activities in the Fafan zone. Recently, an international NGO started directly participating in the implementation of anti-FGM/C programmes after the Ethiopian government embarked on political and legal reforms, including amendment of the CSL. Local NGOs were engaged in various activities including supporting school clubs working on harmful traditional practises, including 
FGM/C. They provided the schools with financial support and equipment for disseminating information (e.g., loudspeakers) focusing on girls and gender issues.

"In our school we learn that girls should not be circumcised for fear of being cursed. We always discuss this. Organisations such as KMG advise us not to undergo circumcision. They also provide us with sanitary napkins to protect students from discomfort when they experience menstruation."

$$
\text { (Girl, IDI, West Arsi). }
$$

Health extension workers (HEW) were involved in disseminating information related to $\mathrm{FGM} / \mathrm{C}$ and educating women at the grassroots level. HEWs were key actors and change agents as they worked closely with the local people. Through day-to-day interaction with local communities, they were involved in teaching women about the negative implications of $F G M / C$. The potential of HEWs to reach local communities and enhance people's awareness of FGM/C was very high because large number of HEWs (two in each rural kebele) were working across remote and rural villages. A key informant from the study district in the West Arsi administrative zone acknowledged the role of HEWs:

"Activities by health extension workers such as facilitating dialogue pertaining to FGM/C and teaching the community about FGM/C are remarkable achievements. The women and children's affairs offices and KMG are very committed to accelerating the abandonment of FGM/C."

(Female government official, IDI, West Arsi).

Healthcare workers were the other change agents who played an important role in accelerating change towards abandonment of $\mathrm{FGM} / \mathrm{C}$. The role of healthcare workers was mainly to teach about the health consequences of FGM/C and provide clinical services as noted by a schoolteacher:

"Every health centre teaches about harmful traditional practises before providing clinical services for the patients."

(Female schoolteacher, IDI, West Arsi)

Parents interviewed noted the role of teachers in informing schoolgirls about FGM/C. Teachers informed girls about FGM/C using various forums especially school clubs such as the girls' clubs. The success of informing schoolgirls was not limited to empowering girls but also had a spiral effect on other members of the community, mainly parents of those girls who gained FGM/C-related knowledge from school clubs. Parents acknowledged the positive contributions of teachers and school clubs:

"I learnt the consequences of FGM/C from my children and health extension workers. Mass media also played an important role...."

(Father of girls, IDI, West Arsi).

Because of extraordinary local resistance to the total abandonment of FGM/C in the Somali context, change actors dropped the total abandonment model and focused on advising community members to shift to the Sunna cut. Consequently, shifting to the Sunna cut emerged as a dominant intervention model in the Somali setting. A suggestion from one woman working as a representative of the women's affairs office at the grassroots level is worth mentioning. As Women's Affairs Offices are the leading government actors implementing and coordinating antiFGM/C interventions, the representative was expected to work as a change agent in accelerating the abandonment of FGM/C. Instead, she encouraged community members to practise the Sunna cut. She also revealed her intention to cut her own daughters.

"Now how can we stop female circumcision? We are not ready to abandon it. I have six daughters and I am not ready to leave them uncut. I prefer the Sunna type for my younger 
daughters. I have already circumcised two daughters... They have undergone Gudnika Faronika. Then I am planning to let the remaining four daughters undergo the Sunna cut.... Now I don't want to let my girls undergo Gudnika Faronika. I prefer the Sunna type and I think it is easy and my four girls will not suffer."

(Female government official, IDI, Fafan)

Findings in the Fafan zone also show the role of religious leaders in supporting the Sunna cut as a means of purifying girls. The support of religious leaders could be one of the major factors that strengthen the inclination towards the Sunna cut. Some religious leaders argue that infibulation contradicts Islamic teachings and therefore implicitly portray the Sunna cut as a religious requirement. This has confused community members, with some practising infibulation as a Sunna cut. A programme implementer working in Jigjiga, the headquarters of the Somali Regional State explains this observation:

"Religious leaders are involved in informing the community... the Sheiks support the Sunna, since the Pharaonic form of mutilation contradicts the religion. But ignoring the teachings of religious leaders, the community practises the Pharaonic form of mutilation in the name of Sunna... Religious leaders are supporting the Sunna form... they say that it was written in the religious Hadiiz [holy Koran]. But no one is sure about it."

(Programme implementer, IDI, Fafan)

Advising community members to practise the Sunna cut is a widely pervasive approach in the Somali administrative zone. HEWs are among the change agents who advise community members to shift to the Sunna type as a means of abandoning infibulation.

"I can say that the culture of Gudnika Faronika has tremendously affected women of our kebele. That is, women have many reproductive health problems and these challenges are caused by Gudnika Faronika. Therefore, I advise women to stop practising Gudnika Faronika and shift toward the Sunna type."

(HEW, IDI, Fafan).

\section{Achievements}

The level of success related to FGM/C programmes implemented in the two study districts varied considerably. In the Somali context, the widely reported change was improvement in awareness, especially related to the negative impacts of infibulation. Most of the study participants considered change in awareness to be a significant positive step. Some key informants, including programme implementers, reflected on the awareness change appreciated by community members. One of the key informants argued that community members' knowledge of health complications of infibulation gave the wrong impression that people were abandoning the practice; and yet the practice continues with some inclination towards the Sunna cut, as the following excerpt shows:

"Today everyone knows the risks of practising the Pharaonic type of FGM/C... Now, many people are well aware of the negative impacts of FGM/C... Awareness of health complications of FGM/C is somewhat reducing the tendency of doing the Pharaonic type [Type III]. As a result, the Pharaonic type of FGM/C is somewhat declining and now many people are practising the Sunna type of FGM/C on their daughters."

(Woman, IDI, Fafan).

The direction of change in the Somali study setting suggest a shift towards the Sunna cut instead of complete abandonment. Notably, the narrative of shifting towards the Sunna cut seemed to be more common in urban areas but not in the rural areas where the majority of community members reside. Practising infibulation was still embedded in the Somali culture and belief system and supported by religious discourses. The practice was associated with cherished values such as 
virginity and purity. It also served as an identity marker for Somali girls and women. Uncut girls/women among the Somali community were considered to be outsiders (e.g., Christians). The response of programme implementers to the strong local resistance to the total abandonment of $\mathrm{FGM} / \mathrm{C}$ in Fafan was noted. The major focus of FGM/C programmes in the study zone was sensitising community members about the health implications of infibulation and advising them to stop practising it. Local resistance to the total abandonment of FGM/C forced programme implementers to reconsider their approaches. One of the key informants working as a programme coordinator in the study zone disclosed that their organisation stopped promoting the total abandonment of $\mathrm{FGM} / \mathrm{C}$ and confined itself to the abandonment of infibulation. Programme implementers were forced to adopt a moderate and pragmatic position, including tolerating (implicitly promoting) discourses and practises related to the Sunna cut. It seems that shifting to the Sunna cut is thought to be the only option for accelerating the abandonment of infibulationwhich is considered a success. As the following quotation shows, people-including change agents such as HEWs-talked about the decline of infibulation and shifts towards the Sunna version. Success in this regard was associated with an increasing awareness of the negative impacts of infibulation and with shifts to the less severe type of cut.

"These days there are many awareness-creation programmes against the practises of 'Gudnika Faronika'. That is, awareness related to the health complications of Gudnika Faronika is widespread and everybody in the kebele knows the problem of the Gudnika Faronika... The causes of those changes are people understanding the negative impacts of Gudnika Faronika. Awareness-creation by health professionals and NGOs has produced some positive changes. The existence of an enabling environment that does not favour the continuation of Gudnika Faronika, as well as an improved knowledge of the health effects of the practice, is a major cause of the decline of the practice of 'Gudnika Faronika' in this community."

(Woman, IDI, Fafan)

The overall situation of FGM/C in West Arsi is more dynamic compared to that of the Somali study setting. Changes involved increasing awareness resulting from a wide range of $\mathrm{FGM} / \mathrm{C}$ programmes implemented in the district and other factors such as improved educational levels of community members. Various manifestations of change/achievements were reported by study participants such as community's achievement in enacting bylaws and enforcing the anti-FGM/C law. Community members in the study site managed to enact a bylaw with elements that prohibit practising $\mathrm{FGM} / \mathrm{C}$ and other harmful customary practises. A schoolteacher appreciated this development:

"In addition to school-based activities, very recently, a bylaw was passed in this community to ban FGM/C. This involved government leaders, community elders, women's associations, teachers and wider community members.... Community members have agreed not to practise any kind of harmful traditional practises."

(Female schoolteacher, IDI, West Arsi)

The other indicator of achievement of FGM/C intervention activities in West Arsi was the involvement and participation of community members, teachers, and respected local leaders. A key informant from a local NGO implementing FGM/C programmes in the community recognised the efforts of the community in developing statements of declarations/bylaws which were subject to approval by the government office.

"The society has begun to take different measures. For instance, they have presented a statement of declaration.... This statement of declaration is to be approved by the districts' House of Representatives and become a bylaw."

(Programme implementer, IDI, West Arsi) 
Programme implementers considered enactment of bylaws to be an important step in strengthening enforcement of the anti-FGM/C law passed by the national government. It was expected that the impacts of the combined effect of the two laws would be big in accelerating the abandonment of the practice in the study area. The enactment of a bylaw by local communities indicates the increasing level of community participation and the consensus of community members to ban $\mathrm{FGM} / \mathrm{C}$ and punish those who practise it.

Community members interviewed in West Arsi supported the claim of programme implementers. Some community members, including women, actively participated in reporting FGM/C-related cases to government authorities. A mother of girls described what her friends did to a traditional cutter in their community in an effort to end FGM/C:

"We advised the traditional circumciser not to circumcise women. We said to her that when you circumcise women; they may die in your hands. Why you do this for 50 birr? Which matters more for you; is it 50 birr or the life of the girl? So, please stop circumcising women. But she refused and continued her practises. Finally, we reported to the zone and she signed not to circumcise.... Yes! Starting from that time she stopped."

(Mother of girls, IDI, West Arsi)

Other general achievements outlined by programme implementers in both study settings included: (i) breaking the silence and encouraging local communities to talk about FGM/C which was a taboo subject; (ii) reaching communities which had been excluded from FGM/C programmes; (iii) persuading traditional cutters to stop cutting and to embrace other means of livelihoods; and (iv) enhancing the participation of community members in FGM/C-related activities such as meetings and trainings.

\section{Tracing change and continuity}

This section explores perceived changes and/or continuity in the two communities via an examination of local perspectives on FGM/C. The overall discourse on FGM/C significantly varied between the two study settings. In West Arsi, study participants claimed that the practice of FGM/C has been declining in recent times. Unlike the past, many girls are abandoning the practice and getting married. The following quote exemplifies participants' views related to the perceived decline of the practice in the West Arsi context.

"There were no women living with their husbands if uncut, in the past.... But now there are a lot of recently married women living in our village without being circumcised. In the past, there was a belief that a girl becomes better/good if she gets circumcised, but we do not force them to do it now.... No one points his/her finger and talk about a woman because she is uncut."

(Mother of girls, IDI, West Arsi)

The situation observed in Fafan is quite different from the one in West Arsi. No study participant reported the abandonment of FGM/C from the Somali study site. Informants from all categories of participants (including key informants, mothers, fathers, HEWs, and girls) reported that FGM/C was still practised across Somali communities. Most of the study participants asserted that finding a single uncut girl/woman was hardly possible in their community.

"I can say that there are no girls who are not circumcised in the community and the community doesn't want to leave girls uncut... Girls must undergo Sunni or Sunna type of Gudnika."

(Woman, IDI, Fafan) 
A young woman who participated in an FGD disclosed how uncut girls are hated by community members, as they are likely to engage in premarital and extramarital sex which is forbidden by the Islamic religion.

"We believe that girls who undergo Gudnika Faronika will not be engaged in premarital and extramarital sex, and they will be good wives. Therefore, being involved in premarital and adulterous sex is absolutely prohibited in our religion, and that is why we hate uncircumcised girls."

\section{(Young woman, FGD, Fafan)}

Data from vignette-based group discussions conducted in the Somali study setting clearly portray a strong opposition to the abandonment of the practice. The vignette-based discussion was about Sofia (a girl waiting for her proposed marriage) and Ali (her fiancé living in the United States). The parents of Sofia agreed to let Sofia undergo infibulation prior to her marriage. In the meantime, Sofia's father and uncle changed their mind and decided that she would not undergo the practice. As a result, Ali cancelled the arranged marriage and got married to another girl who had undergone infibulation. When asked whether they would support the decision of Sofia's father and uncle, most of the participants in the FGD rejected the decision taken by Sofia's father and uncle as demonstrated in the following excerpts:

"Girls who undergo Gudnika Faronika are much better than uncircumcised girls since men can trust [them] and no one can trust uncircumcised girls.... Girls who undergo Gudnika Faronika are virgins, and uncircumcised girls are not virgins."

(Adult woman, FGD, Fafan)

"No! I don't support Sofia's father and uncle because they rejected circumcising Sofia. Totally, I disagree with the idea that girls should remain uncircumcised."

(Young woman, FGD, Fafan)

Regarding the type of FGM/C practised among the Somali community, most of the participants were of the view that nothing had changed, and that infibulation is still popularly practised. A few respondents mentioned that there was a shift towards less severe cutting, commonly referred to as the Sunna cut, especially in urban areas.

\section{Continuity in Fafan, Somali region}

Participants were asked to outline the benefits of $\mathrm{FGM} / \mathrm{C}$ as a means of generating insights into continuity and change around the practice. The role of $F G M / C$ in enhancing girls' marriageability was reflected by study participants when they described the implications of remaining uncut for marital opportunities of Somali girls. In-depth interview and group discussion participants reported that uncut girls cannot find a husband in the Somali cultural setting. A 37-year-old married Somali woman and a schoolgirl described the relationship between $\mathrm{FGM} / \mathrm{C}$ and marriageability in the Somali context:

"Uncircumcised girls will not get husbands. Many parents, unmarried young men, elderly people, clan leaders, and religious leaders support that a girl must be circumcised like boys. That is, female circumcision is much valued and mothers who support their daughters to remain uncircumcised will make them fail to get good husbands."

(Woman, IDI, Fafan)

"Uncircumcised girls are disregarded and no one will marry them. Everyone will point fingers to any uncut girl and she will be insulted. She will be called 'Buryo qab' [long clitoris] 
and this is the common insult for uncircumcised girls. They are stigmatised and no girl can freely interact with community members. It will be very difficult for uncircumcised girls to live in our kebele"

$$
\text { (Girl, IDI, Fafan) }
$$

Some participants of the study described the benefits of FGM/C focusing especially on infibulation. According to their views, infibulation plays an important role in enhancing the social value of an infibulated girl and the prestige of her family and husband. A health extension worker from the Somali study site magnified the relationship between FGM/C, purity, and virginity. She stated that FGM/C that involves partial sealing of the female genital organ increases girls' marriageability by maintaining their virginity and purity.

"Among the community a woman who has undergone circumcision and remained sealed is highly valued and marrying to such a lady was seen as a prestige for both the man marrying her and the girl's family."

$$
\text { (HEW, IDI, Fafan) }
$$

Virginity and purity are essential to enhance marriageability of girls in the Somali context. The girl must be halal (pure/clean) and a virgin to get married. Study participants reported that the virginity of girls, whether they remain sealed or not, would be checked prior to marriage and those found unsealed would be subjected to mistreatment including rejection by the bridegroom and his family.

"Girls who do not undergo Gudnika Faronika are viewed as morally weak and uncontrolled and, thus, a dishonour towards the family reputation. Those who fail the pre-marriage virginity check may face social isolation, become unqualified for marriage, and in some cases, ignored by their own family. In addition to marriage denial, girls who don't undergo circumcision would face insulting songs, and social rejection."

$$
\text { (Female community leader, IDI, Fafan) }
$$

The notion of purity was highly emphasised among Somali study participants. Terms such as haram and halal were repeatedly mentioned by study participants to refer to impurity and purity of girls and women. This indicates that FGM/C, especially infibulation, is considered to be not only a means of preserving the virginity of girls, but also a process of purifying and making them spiritually clean. The notion of purity/cleanness shared by study participants was expressed in religious terms, such as halal as opposed to haram (spiritual impurity). This reveals that FGM/C was embedded in both the Somali cultural tradition and Islamic religion.

"Most mothers say Gudnika Faronika is good for making girls clean and keeping them virgins until marriage. Therefore, the practice is highly favoured as culturally right, as it upholds girl's virginity.... If a girl undergoes Gudnika Faronika she is considered 'Halalen' or clean. If a girl remains uncircumcised, she would be considered 'Haram, 'or unclean, and she would be isolated from the community."

(Girl, IDI, Fafan)

The other perceived advantages of FGM/C frequently mentioned by Somali IDI participants were: protecting girls, controlling sexual desire of girls and women, and respect. When Somali study participants talked about controlling sexual desire, they focused on infibulation which involves cutting as well as partial sealing of the female genital organ. They were of the view that infibulation safeguards the virginity of girls before marriage, increases loyalty of women during marriage, and maintains family honour. 
"Gudnika Faronika is believed to calm sexual desire in women, ensure virginity before marriage and fidelity during marriage, and maintain family honour."

$$
\text { (Father of girls, IDI, Fafan). }
$$

"Gudnika Faronika is believed to secure a girl's or woman's virginity prior to marriage and guarantee loyalty after marriage. Therefore, many mothers still believe that Gudnika Faronika protects a girl's virginity and the respect of her family."

$$
\text { (Father of girls, IDI, Fafan) }
$$

To explore changes in norms and practises at the community level, focus group discussions were conducted to gather data on the community's perceived advantages and disadvantages of $F G M / C$. Two FGDs were held in Fafan zone, involving young women and old women. Findings generated through factorial analysis of FGD data from Fafan are summarised in Table 2.

\section{Table 2: Summary of factorial analysis of perceived advantages of FGM/C in Fafan zone.}

\begin{tabular}{|l|l|l|}
\hline Perceived advantages & Young women & Old women \\
\hline Respect & + & + \\
\hline Marriageability & ++ & + \\
\hline Control sexual desire & + & + \\
\hline Purity & & + \\
\hline Virginity & & ++ \\
\hline
\end{tabular}

Symbols of concordance/discordance and their description

$++\quad$ Raised with high emphasis, with positive consensus

$+\quad$ Raised with low emphasis, but with positive consensus

+ +- $\quad$ Raise with low emphasis, but disagreement

$++/-\quad$ Raised with high emphasis, and disagreement

- $\quad$ Raised with low emphasis, but with negative consensus

- - $\quad$ Raised with high emphasis, with negative consensus

Blank Theme not raised

The factorial analysis revealed that FGM/C was essential in enhancing the marriage prospects of girls in Fafan. Marriageability was discussed as one of the benefits of FGM/C in both young and old women's group discussions but with different levels of emphasis. It was raised with high emphasis and positive consensus among young women. Marriageability was also raised as an advantage of FGM/C among old women but with low emphasis and positive consensus.

Young and old women in Fafan mentioned controlling sexual desire as one of the advantages of FGM/C. The role of the practise in lowering the sexual desire of girls and women in the Fafan zone was raised with low emphasis but with a positive consensus by women participants in the young and old FGD categories. A 37-year-old married Muslim woman aptly described this benefit:

“Women's sexual desires are controlled and women are not forced into prostitution by despair and for financial reasons. Therefore, it's to keep a girl a virgin until marriage."

(Mother of girls, FGD, Fafan)

Purity was one of the most frequently raised advantages of FGM/C in IDI data collected from the Fafan study site. In the factorial focus group analysis, only old women raised purity as an advantage of practising FGM/C with low emphasis but with positive consensus. Only participants in the older women's FGD in Fafan raised virginity as an advantage of the practice with high emphasis and positive consensus. Respect was mentioned as an advantage of FGM/C by both young and old women who were FGD participants in Fafan, with low emphasis but with positive consensus. The excerpt, below, from a 42-year-old married woman exemplifies the association. 
"Female circumcision is an integral part of the rites of passage that confers a sense of pride and status to girls who undergo the procedure".

(Mother of girls, FGD, Fafan)

\section{Change in West Arsi, Oromia region}

The findings related to perceived advantages of FGM/C generated from the West Arsi data have some similarities and differences to the findings in Fafan. Similar to the Somali findings, marriageability and purity are the most frequently reported perceived benefits of $F G M / C$ in the West Arsi study site. However, the numbers of IDI participants who mentioned marriageability and purity as advantages of FGM/C were smaller compared to the frequency of responses from the Somali data. Unlike Somali participants, West Arsi study participants noted that the association between FGM/C and marriageability was very strong in the past but the association had weakened in recent times.

"Both circumcised and uncircumcised are treated equally. Circumcision is not determining marriage. Marriage is determined by wealth and not by FGM."

(Girl, IDI, West Arsi)

"Young men have understood everything...they have a positive attitude towards uncut girls. Young men want to marry uncircumcised girls; they do not want circumcised girls."

(Mother of girls, IDI, West Arsi)

Similarly, findings from West Arsi reveal that the association between FGM/C and purity was strong in the past but declining in recent times. A grade six girl who was interviewed reported that uncut girls were considered as Najisa (spiritually impure uncut girls) in the past, but currently young people do not consider uncut girls to be impure.

"In the past, girls who were not circumcised were considered dirty and to have something Najisa. Boys did not want an uncircumcised girl because she was perceived as unclean. These days, young boys do not bother about FGM/C. Young boys want marriage. They do not worry about FGM/C. Only mothers know whether girls undergo FGM."

(Girl, IDI, West Arsi)

Controlling sexual desire was also mentioned as a benefit of practising FGM/C in West Arsi. There was a belief that uncut girls/women have an extraordinary sexual desire that would push them to extramarital sex and hence unstable marriage. Study participants claimed that FGM/C plays an important role in curbing the sexual desire of girls and women. The following excerpts illustrate the perceived advantage of $\mathrm{FGM} / \mathrm{C}$ in controlling sexual desire.

"Among our society, it is believed that a circumcised woman would have no irresistible sexual desire. So, she won't aspire to have sexual intercourse with different men. This would, in turn, help her live with her husband for a long period of time. She would stick to her husband rather than looking for different men for sexual intercourse."

(Religious leader, IDI, West Arsi)

"This community believes that girls who are uncircumcised are sexually very active and deviate from norms of sexuality in the community. Girls are expected to be calm. FGM/C serves this purpose in this community. Unless girls undergo FGM/C, people perceive that they are not sexually satisfied and thus look for other husbands."

(Female Schoolteacher, IDI, West Arsi) 
Respect and family honour were the other benefits of practising FGM/C mentioned by study participants in West Arsi. Unlike Somali participants, participants in West Arsi portrayed the relationship between $\mathrm{FGM} / \mathrm{C}$ and respect mainly focusing on the past. For example, a married woman aged 25 years reported that in the past FGM/C conferred prestige to the family as a cut girl was considered pure and ready for marriage.

"In the past, the benefits of FGM/C were related to family prestige, purity of the girls and preparation for marriage."

(Mother of Girls, IDI, West Arsi)

Another study participant highlighted the importance of FGM/C in elevating the girl to a position of being respected as she was about to get married.

"You know, after a bride's family agree to give their daughter for marriage, and she is circumcised, no one would approach her for different purposes such as playing or chatting. Everybody would respect her because she is already on the way to marry somebody.... So, circumcision would bring her respect."

(Father of girls, IDI, West Arsi)

To assess changes in norms and practises at the community level, four FGDs were conducted in West Arsi involving young women, old women, young men, and old men. Findings on perceived advantages of FGM/C are summarised in Table 3. Out of the four FGDs conducted in West Arsi, marriageability was raised as a benefit of $F G M / C$ in only one of the group discussions. It was raised with low emphasis but with negative consensus among participants of the young men's FGD. One of the participants, a 25-year-old farmer, stated that circumcision was important in increasing the marriageability of a girl. But this view was challenged by another participant in the group. The second participant, a 32-year-old farmer, argued that female circumcision did not have any advantage. Different from findings in Fafan, associations between FGM/C and respect, control of sexual desire, purity, and virginity were not mentioned.

Table 3: Summary of factorial analysis of perceived advantages of FGM/C in the West Arsi Zone.

\begin{tabular}{|l|l|l|l|l|}
\hline $\begin{array}{l}\text { Perceived } \\
\text { advantages }\end{array}$ & $\begin{array}{l}\text { Young } \\
\text { women }\end{array}$ & $\begin{array}{l}\text { Old } \\
\text { women }\end{array}$ & $\begin{array}{l}\text { Young } \\
\text { men }\end{array}$ & $\begin{array}{l}\text { Old } \\
\text { men }\end{array}$ \\
\hline Respect & & & & \\
\hline Marriageability & & & +- & \\
\hline Control sexual desire & & & & \\
\hline Purity & & & & \\
\hline Virginity & & & & \\
\hline
\end{tabular}

Symbols of concordance/discordance and their description

$++\quad$ Raised with high emphasis, with positive consensus

$+\quad$ Raised with low emphasis, but with positive consensus

$+/-\quad$ Raise with low emphasis, but disagreement

$++-\quad$ Raised with high emphasis, and disagreement

- $\quad$ Raised with low emphasis, but with negative consensus

- - $\quad$ Raised with high emphasis, with negative consensus

Blank Theme not raised

\section{Knowledge on the consequences of FGM/C and acceptability of change}

Study participants were asked to talk about the drawbacks of FGM/C. In West Arsi, participants mentioned that FGM/C predisposes women to fistula and transmitted diseases such as HIV/AIDS through the traditional cutter's contaminated blades. 
"People are recognising the negative impacts of FGM/C during delivery.... People know that FGM/C has far-reaching health complications such as fistula."

(Woman, IDI, West Arsi)

Some participants mentioned transmission of infectious diseases, bleeding, and physical injuries as disadvantages of practising FGM/C. A father of girls in West Arsi outlined some of the implications of $F G M / C$ including bleeding.

"FGM/C is usually practised by traditional practitioners who have no deep knowledge about the practise and its consequences. As a result, there is less care during FGM/C. For instance, they practise FGM/C with old and unclean blades. This could lead to different transmitted disease. In addition to bleeding and physical injury, FGM/C could cause infection around the genital organ because the circumcisers have no knowledge about caring for the wound created due to FGM/C."

(Father of girls, IDI, West Arsi)

Problems during sexual intercourse, especially lack of sexual satisfaction, were reported by a few respondents. A study participant from the women's affairs office portrayed the negative impacts of $\mathrm{FGM} / \mathrm{C}$ on sexual satisfaction, which in some cases could lead to divorce.

"There is an increase in complaints and appeals coming to our office because of the disagreement between the husband and the wife....There is a case when a husband has complained that his wife is not satisfying him sexually and consequently, he is visiting other women for sex.... When we asked his wife why she doesn't fulfil his sexual needs, she confesses that she doesn't have a sexual feeling at all.... We suspect the cause may be related to circumcision... As long as their sexual feeling is not matched, it may contribute to the breaking of family."

(Woman, IDI, West Arsi)

In the Fafan zone, findings were dominated by an increasing awareness surrounding the negative implications of infibulation, especially its impact on health and well-being of girls and mothers. There was some inclination towards abandoning the severe type of FGM/C and shifting to the Sunna cut but resistance to total abandonment of the practise was very strong.

"All these people practise female circumcision just because of their cultural traditions not because of religious influence.... Today many people understand the negative impacts of female circumcision and the awareness created had led to some changes, but there are no lasting changes yet, as the practise continues as usual."

(Woman, IDI, Fafan)

With regard to acceptability of change, findings from vignette-based FGDs revealed that participants in Fafan supported the continuation of infibulation. The vignette employed in the Somali study site was about Sofia and her fiancé Ali living in the United States. Sofia's parents had agreed to let their daughter undergo infibulation as a prerequisite to her marriage. In the meantime, Sofia's father and uncle rejected the idea of infibulating Sofia, as a result Ali cancelled the proposed marriage and got married to an infibulated girl from the same district. All the participants in the FGDs in Fafan supported the decision of Ali who cancelled the proposed marriage. The following excerpts demonstrate the support for the continuation of infibulation:

"We support Ali's choice. We all believe infibulation is our traditional custom and is part of our culture that defines our identity and brings us together."

(Old man, FGD, Fafan) 
"We support Ali's decision.... Here in our kebele no one will marry an uncircumcised girl; this is the reality.... Ali looked for a good wife and Sofia's father and uncle wanted to offer him a bad girl for marriage."

(Old woman, FGD, Fafan)

Findings from West Arsi data show that attitudes towards FGM/C are mixed, with majority of community members supporting the abandonment of FGM/C while a few others support the continuation of the practice. Generally, FGM/C practises are being challenged as the number of girls abandoning the practice is increasing and younger men tend to marry uncut girls. The following quotations illustrate attitudinal changes towards abandonment of the practice.

"Those girls have changed their mindset believing that this thing [FGM/C] is an old culture and have avoided or escaped female circumcision. Such women argue that being healthy is better than undergoing circumcision. The main thing that helped them change their behaviour is education."

(Religious leader, IDI, West Arsi)

"I am telling you what I know about my locality. In a very rare situation people may practise female circumcision in secret....There is no ceremony and open celebration of female circumcision. Female circumcision is losing its value over time. People developed negative attitudes towards the practice. No one appreciates the practice through song and festivities."

(Father of girls, IDI, West Arsi)

The vignette employed in FGDs in West Arsi was about Jitu, a newly married uncut woman married to an educated young man. Jitu's husband asked her to undergo FGM/C, influenced by the social pressure from his relatives and other community members in his village. When asked what advice they would give to solve the problem, most of the group discussion participants advised her to stay uncut. Some participants argued that Jitu would not suffer alone as the current anti-FGM/C law supported her. A participant in the young men's FGD noted that the current time is different from the past and that one cannot easily violate the rights of girls and children these days.

"I advise her to talk to concerned officials such as women, children, and youth affairs office, the police, and others. And I also personally can help Jitu to get in contact with the concerned officials. Rather than directly defending her from community members including her husband, I would follow the legal procedure and report the case to the women's affairs office to support her legally."

(Young man, FGD, West Arsi).

Findings from factorial focus group analysis are summarized in Table 4 . The overview grid demonstrates a strong support for the abandonment of the practice in West Arsi. Participants of the four FGDs (young and old women and men) in West Arsi stated that abandonment was possible and acceptable.

Table 4: Summary of factorial analysis on acceptability of change

\begin{tabular}{|l|l|l|l|l|l|l|}
\hline \multirow{3}{*}{ Acceptability of change } & \multicolumn{3}{|l|}{ West Arsi Zone } & \multicolumn{2}{l|}{ Fafan Zone } \\
\cline { 2 - 8 } & Women & Men & Women \\
\cline { 2 - 8 } & Young & Old & Young & Old & Young & Old \\
\hline Abandonment & ++ & ++ & ++ & ++ & -- & \\
\hline Medicalisation & -- & + & - & -- & + & \\
\hline Shifting to less severe types & $+/-$ & -- & $+/-$ & -- & -- & \\
\hline
\end{tabular}


As exemplified in the following excerpts, participants supported the abandonment of FGM/C regardless of their age.

"Here in our community stopping this practice has a public acceptance. Our families are learning, and they also teach us what they learned."

(Old man, FGD, West Arsi)

"Yes, it is acceptable.... Circumcision should be abandoned since it has a lot of effects. Since circumcision brought various problems, it should be abandoned. People who perform female circumcision should be advised."

(Young woman, FGD, West Arsi).

In contrast, findings from the Somali data revealed that the issue of abandonment was raised with high emphasis but with negative consensus among young women FGD participants. They stated that abandonment of the practice was impossible in their community.

"Totally no! People still believe in old cultural traditions and I don't think that it would be acceptable to abandon Gudnika Gabadha [FGM/C] since there are no good alternatives to Gudnika Gabadha."

(Young woman, FGD, Fafan)

Medicalisation of FGM/C has been widely observed in many parts of Africa including Egypt and Sudan. Changes to medicalisation were mostly reported in West Arsi as elaborated by a programme officer who had been implementing anti-FGM/C interventions in West Arsi zone.

"There are also rumours that girls undergo FGM/C at clinics. We have no evidence regarding who does it, when and how it is conducted. Yet, community members still raise [the fact] that FGM/C is practised at clinics. This demands further investigation."

(Programme implementer, IDI, West Arsi).

Medicalisation of FGM/C was not strongly reported in the Somali context. However, a few community members noted the importance of having to access FGM/C services in healthcare facilities in the future.

"We don't mind our girls being cut by a health professional;...it will be a great transformation for us. Currently we are practising Gudnika Faronika secretly and going to far areas. It will be a great opportunity if we get health facilities here in our kebele and circumcise our daughters just like the boys."

(Old woman, FGD, Fafan)

Findings from the two sites on shifts in the types of FGM/C considerably varied. In West Arsi, a shift towards less severe types of $F G M / C$ was rejected by participants in the old women and men FGDs. In Fafan, findings showed a strong opposition to shifting to less severe type of $F G M / C$, locally called the Sunna cut.

"All types are unacceptable. Nobody told us the less severe has no impact and the more severe has an impact. They told us all types of circumcision are harmful."

(Young woman, FGD, West Arsi)

"Totally no...We only know Gudnika Faronika and we are still practising it."

(Young woman, FGD, Fafan)

\section{FGM/C and girls' agency: Change and continuity}

Findings from the two study sites show different levels of girls' agency to make decisions related to $\mathrm{FGM} / \mathrm{C}$. The West Arsi data revealed that the number of uncut girls getting married was 
increasing. However, uncut girls face challenges in remaining uncut, especially after they get married. The major challenge comes from the mothers-in-law who pressure their daughters-in-law to get cut. Some of the newly married girls reject the proposal of undergoing FGM/C and decide to end their marriage when the pressure persists. The following excerpt from a schoolteacher illustrates the determination of some young women to abandon FGM/C at the expense of their marriage.

I have talked to five girls who were divorced and returned to school. They are gender club members. Three of them were circumcised while two of them were uncircumcised. Those who were not circumcised told me that they rejected FGM/C proposed by their mothers-inlaw. As a result, they got divorced and decided to continue with their education."

(Female schoolteacher, IDI, West Arsi).

It is important to look into the social setting of the study community to understand girls' agency to make FGM/C-related decisions in West Arsi. As the field data show, there were some changes that empowered girls to make decisions related to their circumcision. One of the recent developments that enhanced girls' decision-making power was the shift from marriage arranged by parents to consent-based or love marriages, as portrayed by the following excerpt.

"Now, both female and male youths have the right to select their partner. This is because the culture of sending one's father to beg a girl's family for marriage has waned. So, today, our children are marrying each other based on their own interest. They [girls] are marrying a person whom they fall in love with."

(Father of girls, IDI, West Arsi)

Girls' agency manifested in different ways including making the decision to abandon the practice and offering counter challenges to social pressure coming from other people. A mother of girls interviewed for this study described the situation as follows:

"Some individual may perceive an uncut girl as crazy; they questioned how she refused to do so, and said that she did not take care of her name and values. But nowadays there are girls who respond to such questions by saying 'who are you to think of my identity and my value?"”

(Mother of girls, IDI, West Arsi)

Other developments that empowered girls to make FGM/C-related decisions were awareness of the anti-FGM/C law, fear of legal sanctions, and awareness of women's/girls' rights to make decisions on matters related to her physical integrity.

In addition to changes enabling girls to make FGM/C-related decisions (e.g., to abandon the practise), some of the changes exposed them to other challenges that forced them to reconsider their decision. As a result of the strong influence of mothers-in-law, some newly married girls decided to undergo FGM/C to establish a good relationship with their in-laws and for fear of social exclusion as the following quotation reveals:

"Girls are not sure whether they can lead a happy life without being cut...Uncut girls are still under pressure. So instead of being insulted by in-laws and husbands they prefer undergoing FGM/C... Girls are not sure whether they can survive community pressure if they are not cut. They continue seeking FGM/C services for fear of insults and stigma."

(Female schoolteacher, IDI, West Arsi).

Interview data collected from West Arsi revealed that mothers-in-law wield substantial power in influencing the choice of girls to either undergo FGM/C or not. Mothers-in-law exercise their influence either by directly demanding that the daughter-in-law get cut or forfeit the marriage, or by applying pressure through the son. 
"The mother in-law pushes her to divorce and go back to her parents. The mother in-law will insult the girl. She will always nag her. She will also insist to her son to do something with his wife. Mothers in-law are weird!"

(Girl, IDI, West Arsi)

The West Arsi findings outlined above depict a dynamic scenario embracing two competing developments: (i) changes that enhance girl's agency to abandon FGM/C (e.g., rights awareness, legal support, love marriage) and (ii) in-law pressure that forces uncut married women to reconsider their decision to remain uncut. Findings generated from the Somali data reveal a different scenario. Unlike girls in West Arsi, Somali girls continue to be excluded from FGM/C-related decisionmaking. Their capacity to make decisions regarding their circumcision is constrained by religious and cultural norms that cherish FGM/C.

\section{FGM/C interventions: Challenges for abandonment}

Programmes implementing $\mathrm{FGM} / \mathrm{C}$ interventions experienced several challenges including: resistance to change, lack of sustainability of interventions, implementation setbacks in the form of trainings, coverage and shortage of funding, and constraints related to legal restrictions.

\section{Resistance from community members}

Resistance to changes related to FGM/C was mostly reported in Fafan zone. This was attributed to a number of reasons including the value attached to $\mathrm{FGM} / \mathrm{C}$ by community members as an important element of their culture. Since a majority of community members still practise FGM/C, efforts to persuade community members to abandon the practice has mostly led to either alteration in the type of FGM/C or the practice being undertaken in secret.

"Significant numbers of people are still practising FGM/C in secret ways taking girls to remote areas for practising the pharaonic type of FGM/C. Attempts to eradicate the practises of FGM/C have been obstructed by cultural tradition."

$$
\text { (Man, IDI, Fafan) }
$$

"We attempted to give awareness in the community, in schools, informing [about] the negative impacts of Gudnika Faronika. We tried to inform people that Gudnika Gabadha is a learned practise but not culture. Nevertheless, the community still upholds Gudnika Gabadha as a cultural tradition."

$$
\text { (Woman, IDI Fafan) }
$$

Although the level of resistance to change in the West Arsi setting seems lower, study participants reported that due to strong cultural values and beliefs attached to $F G M / C$, programme implementers experience challenges in persuading community members, especially women, to abandon the practice. Some key informants complained that there are instances where community members pretend to have understood the harms of FGM/C and agree to stop it during awarenessraising meetings but continue practising it when they go back home.

"In these areas, mothers are highly overwhelmed with a traditional view which in turn creates difficulties for us to be successful in abandoning female circumcision in the area. They don't trust us when we tell them the impact of FGM/C. Thus, though we are still trying, it is very difficult to convince them, in order to bring attitudinal change."

(Woman, IDI, West Arsi) 
"For the time being, community members accept that FGM/C is harmful but that is not from their 'heart.' They continue doing FGM/C because they have been doing it over a generation. People in this area are resistant. I have organized a meeting about abandoning FGM/C with women. They resisted and asked me several questions. They simply laughed and disturbed the meeting."

(Female schoolteacher, IDI, West Arsi).

In the Somali setting, the very meaning of FGM/C is contested. For some people only infibulation is considered to be FGM/C. Moreover, infibulation is considered illegal whereas Sunna is perceived as a legal practise. This is an important issue because abandoning FGM/C is considered to be abandoning the severe type of FGM/C. Shifting to the Sunna cut is also portrayed as abandonment. These developments lead to a multi-layered challenge to interventions aimed at accelerating the total abandonment of $\mathrm{FGM} / \mathrm{C}$ as it paves the way for people to: practise infibulation secretly, practise infibulation in the name of the Sunna cut, and practise the Sunna cut as a legally accepted type of cutting. A programme coordinator working for an NGO in the Fafan zone narrated how her organisation was forced to "accept the reality on the ground" and stop denouncing the Sunna cut.

"Yes, we have passed through many challenges and many people have insisted that they have stopped FGM/C but they have continued practising it secretly....Then, it totally becomes difficult to officially denounce the Sunna practise and now the project implementers are forced to accept the reality on the ground that people don't want to officially stop the Sunna cut, but people will continue practising the Sunna legitimately.... We have also attempted to stop people from practising the Sunna version and no one has accepted this call since people associate the Sunna practise with the Islamic teachings."

(Programme implementer, IDI, Fafan).

The other prominent challenge that has encouraged resistance by the community in the Fafan zone is the role of religious leaders who encourage followers of Islam to practise the Sunna cut. People consider the Sunna cut to be a religious requirement and a process of purifying girls/women-which is the message passed down by the religious leaders.

\section{Lack of sustainability}

The lack of sustainability of anti-FGM/C interventions related to the challenges of poor communication and lack of feedback from the community to programmes and vice versa. There was also a lack of continuity of FGM/C programmes, especially training, with a lack of collaboration among entities implementing a myriad of $\mathrm{FGM} / \mathrm{C}$ interventions. The short timeframe for implementing interventions was also noted as a challenge. Participants highlighted that for successful behaviour change, programmes needed to adopt an intensive implementation approach sustained over a longer period of time.

"The majority of community members forget what they learned when they go back home so there is a need to give the training repeatedly without being bored.... It needs timely refreshing so that we to make the community understand the issue well. However, the community doesn't have a negative attitude towards the training... the weakness is it was not continuous and regular. It was provided after a long interval after the community forgot the earlier training."

(Local leader, IDI, West Arsi). 
"For instance, after getting funds, some organisations work on this thing [FGM/C] for either one year or two years. Within such a short period, the society does not even understand what the programmes are about.... At the time when the society understands the programmes, the organisations would leave the areas. So, the society would get back to the practises that they were performing."

(Programme implementer, IDI, West Arsi).

Study participants working for organisations implementing FGM/C programmes associate this problem with a shortage of funding and resources to implement programmes for longer periods, and cover wider areas and communities. Programme implementers complained that they could not expand their programmes to more communities for various reasons including covering high perdiem requests from leaders.

"For we do not have per diem payment for community conversation; it is difficult to call participants from distant places after paying for transport. It was a must to have at least one community conversation in each zone. However, in a Ganda [unit of local administration in a rural area] having more than 1000 inhabitants, we have only one community conversation having 50 members. This is because of the shortage of budget."

(Programme implementer, IDI, West Arsi).

"We cannot invite top-level religious leaders to come here and teach and give orders to the lower-level religious leaders. While inviting such top-level men, they need you to pay them between 3000 and 5000 Ethiopia Birr per either three or four days. The government should change this thing (70/30) in order to help us work with our full power or capacity."

(Programme coordinator, IDI, West Arsi).

\section{Poor selection of change agents}

The other challenge that constraints the success of $\mathrm{FGM} / \mathrm{C}$ interventions is associated with poor targeting/selection of change agents to spearhead implementation of interventions. Some study participants argued that change agents participating in capacity-building trainings are not selected properly. The problem involves selection of trainees considering personal relations and attachments with government offices and officials. A schoolteacher argued that provisional trainees needed to be selected carefully considering merit and commitment to help their respective communities accelerate the abandonment of FGM/C. In reality, she argued, trainees are selected through informal relationships, social ties, and attachment with government offices so that they could get some benefits such as a per diem.

\section{Reluctance of religious leaders}

Participants observed that in addition to demanding per diems, some trainees do not act as change agents once they move back to their respective communities. This included the reluctance of religious leaders to denounce $\mathrm{FGM} / \mathrm{C}$ and teach their congregants to abandon the practice.

During awareness creation on FGM/C, religious leaders were there. They trained and knew about FGM/C in good manner. However, none of them approved it or brought the issues to their church or mosques and they haven't preached to the community.

(Mother of girls, IDI, West Arsi)

\section{Exclusion of boys}

The other challenge related to targeting of only girls and not boys. Study participants reported that interventions aimed at empowering/informing girls are confined to school premises. Girls do not find other opportunities outside the school setting to learn about the negative implications of FGM/C. Exclusion of boys from school-based intervention activities was mentioned as a challenge. For example, school clubs working on harmful traditional practises, including FGM/C, exclude 
schoolboys from discussions related to FGM/C, and yet these boys could also be used as change agents in the community.

"On Thursday, every week we discuss harmful traditional practises. Girls discuss alone while boys have their own team to play football. Every Thursday, after we have learned for three consecutive classes, boys leave the class to play while girls discuss harmful traditional and gender inequality issues."

(Girl, IDI, West Arsi).

\section{Legal restrictions}

The major challenge reported by key informants working for local NGOs was related to legal restrictions of the Charity and Societies Law of 2009. The law prohibited local NGOs generating more than $10 \%$ of their annual budget from outside sources (outside Ethiopia) from implementing right-based programmes including FGM/C interventions. Hence, organisations working on FGM/C were forced to craft their programmes carefully to avoid the legal implications of their activities. The following quotation reveals this reality.

"The government law has prevented us (NGOs) from explicitly talking about circumcision. It has limited us not to talk about the rights of women and FGM/C. We cannot even talk about law and articles in front of the society because we have been constrained. So, this has become the biggest challenge not to extensively addressing the issue of circumcision."

(Programme implementer, IDI, West Arsi).

\section{Summary of Findings}

The first objective of this study was to explore how FGM/C interventions implemented in the West Arsi and Fafan administrative zones have influenced community values and deliberations on FGM/C. Programme implementers used various approaches to inform community members and encourage them to abandon FGM/C. The main FGM/C intervention approaches were community conversation, legal intervention, religious-orientation and health-risks approaches. Study findings reveal that interventions implemented in the two study sites have had varied levels of influence on community values and deliberations related to FGM/C.

FGM/C interventions have been implemented in both study communities by different actors. The first set of actors are government agencies including women's affairs offices, health bureaus, healthcare institutions, and schools. Government actors have a greater level of freedom to implement anti-FGM/C programmes. The activities of local NGOs implementing $\mathrm{FGM} / \mathrm{C}$ programmes were constrained by the restrictions of the Charities and Societies Law endorsed in 2009. International organisations were totally excluded from direct involvement in $F G M / C$ interventions - their role was limited to providing government actors and local NGOs with technical and financial support. The law prohibits local NGOs from rights-based interventions including FGM/C programmes if they receive more than $10 \%$ of their annual budget from abroad. In response to this restriction, local NGOs craft their programmes carefully, without explicitly mentioning $\mathrm{FGM} / \mathrm{C}$ or hiding it under broader programmes (e.g., reproductive health). The legal restrictions constrained the potential of local NGOs to expand their programmes, reach wider areas and communities, and accelerate the abandonment of the practise. The endorsement of the CSL led to a significant reduction in the number of local NGOs implementing rights-based programmes. Nonetheless, it is important to note that the restrictions of the CSL are becoming relaxed as the law is replaced by a new law, the Organization of Civil Societies Proclamation, endorsed in 2019. The achievements of local NGOs were also constrained by other factors including a shortage of 
funding, lack of sustainability/continuity of intervention activities, local resistance to change, and poor implementation capacity (FDRE 2009).

The second objective of the study was to explore changes in FGM/C norms and practises. Changes in FGM/C-related norms and practises observed in the two study settings varied significantly. As compared to the Somali study context, the situation in West Arsi is more dynamic and changing. Changes in West Arsi are not limited to an increasing awareness of health risks of FGM/C and the anti-FGM/C law. Community members are involved in enacting bylaws and enforcing the anti-FGM/C law. Community values and norms related to marriageability, purity, and respect-perceived advantages of $\mathrm{FGM} / \mathrm{C}$-are challenged. Changes in norms associated with $\mathrm{FGM} / \mathrm{C}$ are followed by abandonment of the practice. Changes in norms and practises are manifested in various ways: the number of girls abandoning $\mathrm{FGM} / \mathrm{C}$ is increasing, uncut girls are getting married, social pressure on uncut girls and their parents is declining, and uncut girls are considered to be modern and educated. Despite these changes, there were some levels of resistance observed in West Arsi. Though the influence of parents in arranging FGM/C has been declining as a result of consent-based/love marriages, uncut girls are exposed to challenges in their marital home mainly propagated by in-laws and people related to their husband's clan. In some cases, mothers-in-law force uncut daughters-in-law to undergo the practice through exercise of their social power. As Mackie and colleagues note in the social norms theory, FGM/C is an interdependent behaviour guided and sanctioned by social norms (Mackie et al. 2015). In this context, newly married uncut women are subjected to pressure to conform to options of either: getting cut and living in peace with their in-laws, rejecting the proposal and living in constant conflict in her new home, or getting divorced to remain uncut. Some women decided to get cut to avoid conflict with their mother-in-law and to establish harmonious relationships with their husband and other members of the family, while others opted out of the marriage in order to remain uncut. Therefore, in-laws' expectations about what their daughter-in-law should do matters a lot in the continuation of $\mathrm{FGM} / \mathrm{C}$ in West Arsi. Hence, interventions that only seek to empower girls to resist $\mathrm{FGM} / \mathrm{C}$ may not be successful in accelerating the abandonment of FGM/C. There is a need for a multifaceted approach targeting community members with influence in decision-making on issues to do with $\mathrm{FGM} / \mathrm{C}$.

The situation in the Somali study setting was quite different. Shifts related to FGM/C were mainly limited to awareness of the health consequences of FGM/C. Significant alterations of FGM/C norms and practises were not observed. The association between FGM/C and marriageability, purity, virginity, and respect is still very strong. Uncut girls are considered haram (impure/unclean) and excluded from social responsibilities. FGM/C is considered to be a process of purifying girls. Community awareness of the health risks associated with FGM/C have not led to abandonment of the practice. Abandoning FGM/C involves a high social risk as sanctions against uncut girls/women include exclusion from social interactions and religious activities. Compared to previous findings (Spadacini and Nichols 1998), findings of this study showed slight changes towards a supposedly less severe type of FGM/C (the Sunna cut) especially in urban areas. Infibulation, popularly known as Gudinka Faronika, is generally still highly cherished and widely practised in the study community despite FGM/C interventions. With reference to the social norms theory, parents and girls in Fafan are subjected to strong social pressure to conform to FGM/C-related social norms. This includes people's beliefs about what other parents/women do-cut their daughters (empirical expectation). Most of them believe that other girls/women have undergone the practice. Community members expect every girl to undergo $\mathrm{FGM} / \mathrm{C}$ (normative expectation) and that uncut girls would face negative sanctions including social exclusion (Mackie et al. 2015).

The third study objective was to assess challenges experienced by actors trying to foster changes in FGM/C norms and practises. Legal restrictions are the major hindrances that constrain the success of FGM/C programmes in the two study sites. Prohibition of implementing rights-based 
programmes and receiving funding from foreign sources limit the capacity of local NGOs to expand the coverage of their programmes with the aim of accelerating the abandonment of FGM/C. For example, programme implementers in Fafan covered very few sections of the local population because of scattered settlements and seasonal mobility of pastoral communities. They also faced strong resistance to total abandonment of the practice. FGM/C interventions in Fafan focused on the abandonment of infibulation, which implicitly encourages the shift to the Sunna cut. Local actors, including health extension workers, explicitly advise community members to shift to less severe forms of FGM/C, popularly referred to as the Sunna cut, to accelerate the abandonment of infibulation. Local discourses also involve misconceptions related to the anti-FGM/C law, which was considered as prohibiting infibulation but not the Sunna cut. As a result of this misunderstanding, some people practise the Sunna cut as if it were legal while others evade legal sanctions by practising infibulation and referring to this as Sunna. The findings in the Fafan zone closely resonate with findings of a similar study conducted in Somalia (Somaliland), which is mainly inhabited by the Somali ethnic group_similar to the Fafan zone. Powell and Yussuf (2018) found that $\mathrm{FGM} / \mathrm{C}$ was framed mainly as either a cultural or religious undertaking. Infibulation was common and considered to be culturally inherited, while the Sunna cut was viewed by many as supported by religious teachings. Similar to respondents in the Fafan zone, respondents in Somaliland generally reported a shift away from the Pharaonic (infibulation) to the Sunna cut, with the transition more common in urban areas.

\section{Limitations}

The study was conducted in only two study sites and therefore findings from this study may not be generalisable to other contexts. Nonetheless, these are "hot spot" communities where many interventions have taken place, and an in-depth understanding of social norms and the dynamics of change can be useful for optimising interventions being implemented in the two study sites.

\section{Conclusion}

This study was conducted in two administrative zones located in Oromia and Somali regional states. The two study sites exhibit varied socio-cultural and religious contexts. The following conclusions are drawn based on the findings from the two study sites.

Government agencies and NGOs have been engaged in implementing FGM/C programmes using community conversation, legal intervention, religious-orientation, and health-risks approaches. Interventions have had different levels of influence on community values and deliberations in the two study settings. Varied levels of change in norms and practises associated with FGM/C were observed in the two study sites. In Fafan, changes are limited to awareness of health risks of $\mathrm{FGM} / \mathrm{C}$ and an alleged slight shift to a less severe type of the practice, locally known as Sunna. Norms sustaining the practice remain intact and supported by religious discourses that portray $\mathrm{FGM} / \mathrm{C}$ as a process of purifying girls. The practice is strongly associated with marriageability, virginity, purity, and respect. The severe type of $F G M / C$ is still cherished with a slight inclination to the Sunna cut. Changes in West Arsi were more dynamic and widespread. Norms and practises related to marriageability, virginity, purity, and respect have been challenged and altered.

The major challenges of interventions implemented to encourage abandonment were associated with legal restrictions on charities and societies engaged in rights-based interventions in Ethiopia. The Charities and Societies Law excluded international organisations from implementing FGM/C interventions which constrained the potential contributions of NGOs in accelerating the abandonment of $\mathrm{FGM} / \mathrm{C}$. The law restricted collaboration between international and local organisations, limited the availability of funding, and weakened the capacity of local NGOs to 
expand their programmes to reach wider areas and communities and accelerate the abandonment of the practise. Notably, the law is gradually being replaced by the Organization of Civil Societies Proclamation endorsed by the Ethiopian Parliament in 2019. The new law allows civil society organisations to participate in advocacy and human rights work. This is a positive step as it will encourage joint efforts of local and global actors in investing in anti-FGM/C programmes to accelerate the abandonment of FGM/C in Ethiopia.

\section{Implications for Programmes and Research}

\section{Programmatic implications}

- An integrative approach in programme implementation, with a clear focus on engaging community members in values deliberation, will likely facilitate community-wide abandonment of FGM/C. Interventions in West Arsi that only seek to empower girls to resist FGM/C may not be successful in accelerating the abandonment of $F G M / C$ as girls face numerous pressures from other community members, especially their mothers-in-law. There is, therefore, a need for a multifaceted approach targeting community members with influence in decision-making on issues to do with FGM/C. In the Fafan zone, working with community and religious leaders will be key as a first step in encouraging community members to not just shift from performing infibulation to lesser cuts but total abandonment of the practise.

- Improving the capacity of change agents, including health extension workers and religious leaders, is essential in accelerating change towards the abandonment of the practise. Training of change agents on behaviour-change approaches, especially on changing social norms, will be helpful in equipping them with skills to engage the local population. Proper selection of change agents through consultation with the local communities will be important in fostering sustainability of interventions and lasting change.

- There isn't a single set of interventions that will work in all settings. Given that findings from the two sites present different scenarios, there is a need for tailored programming that is sensitive to the local realities. For example, interventions implemented in Fafan will have to be tailored to the reality that the practise is still deeply rooted with sanctions for community members who do not conform. In West Arsi, interventions should be targeted to accelerate the change that is already happening as reluctant community members move towards abandonment.

\section{Research implications}

- A quantitative survey measuring communities' readiness for FGM/C abandonment is needed as a follow-up inquiry in both the West Arsi and Fafan administrative zones. Finding out where the two communities are with regard to stages of readiness for total abandonment of FGM/C will provide important data for effective programming.

- Expanding the application of vignettes and indirect questioning methods in the study of sensitive issues such as FGM/C. In contexts where sensitive issues such as $F G M / C$ have been prohibited by law and attract legal punishment, it is challenging to get genuine responses from study respondents. It is therefore critical for researchers to develop data-collection tools that will aid the generation of quality data reflective of the true situation on the ground. The use of vignettes and other indirect questioning approaches have the potential to reduce social desirability commonly experienced in the study of sensitive topics such as FGM/C. 


\section{References}

28TooMany. 2013. Country Profile: FGM in Ethiopia. Available at: https://www.28toomany.org/static/media/uploads/Country\%20Research\%20and\%20Res ources/Ethiopia/ethiopia country profile v1 (October 2013).pdf

Abusharaf, R.M. 1995. "Rethinking feminist discourses on female genital mutilation: The case of the Sudan," Canadian Woman Studies 15(2-3): 52-54.

Berkowitz, A.D. 2004. The social norms approach: Theory, research, and annotated bibliography Available at: http://www.alanberkowitz.com/articles/social_norms.pdf.

Bernard, H.R. 2011. Research Methods in Anthropology: Qualitative and Quantitative Approaches. OXford: Rowman Altamira.

Bicchieri, C., T. Jiang, and J.W. Lindemans. 2014. A Social Norms Perspective on Child Marriage: The General Framework. New York: UNICEF.

Boyden, J., A. Pankhurst, and Y. Tafere. 2013. "Harmful Traditional Practices and Child Protection: Contested Understandings and Practices of Female Child Marriage and Circumcision in Ethiopia." Working Paper No. 93. London: Young Lives. Available at: https://www.younglives.org.uk/sites/www.younglives.org.uk/files/YL-WP93_Boyden.pdf.

Central Statistics Authority (CSA). 2013. Population Projection of Ethiopia for all Regions at Woreda Level (2014-2017). Addis Ababa: Central Statistics Authority.

Central Statistical Agency (CSA) [Ethiopia] and ICF. 2016. Ethiopia Demographic and Health Survey 2016. Addis Ababa and Rockville, MD: CSA and ICF.

Central Statistical Agency (CSA) [Ethiopia] and ORC Macro. 2006. Ethiopia Demographic and Health Survey 2005. Addis Ababa and Calverton, MD: CSA and ORC Macro.

2001. Ethiopia Demographic and Health Survey 2001. Addis Ababa and Calverton, MD: CSA and ORC Macro.

Creswell, J.W. 2007. Qualitative Inquiry and Research Design: Choosing Among Five Approaches. 2nd Edition. Thousand Oaks, CA: Sage Publications, Inc.

Dagne, H.G. 2009. "Ethiopia: Social Dynamics of Abandonment of Harmful Practices. Experiences in Four Locations." Innocenti Working Papers no. 2009-07, Florence: UNICEF.

Ercevik Amado, L. 2004. "Sexual and bodily rights as human rights in the Middle East and North Africa," Reproductive Health Matters 12(23): 125-128.

Federal Democratic Republic of Ethiopia (FDRE). 2009. Proclamation for the Registration and Regulation of Charities and Societies. No. 621/2009.

Hagmann T., and J. Abbink. 2011. "Twenty years of revolutionary democratic Ethiopia, 1991 to 2011," Journal of East African Studies 5(4): 579-595.

Hebo, M. 2014. "Evolving markets, rural livelihoods, and gender relations: The view from a milkselling cooperative in the Kofale district of West Arsi, Ethiopia," African Study Monographs 48: 5-29.

Hussein, M.A., A.A. Adem, and M.A. Mohammed. 2013. "Knowledge, attitude and practice of female genital mutilation among women in Jigjiga Town, Eastern Ethiopia," Gaziantep Medical Journal 19(3): 164-168.

Knodel, J. 1993. "The design and analysis of focus group studies: A practical approach," Successful Focus Groups: Advancing the State of the Art 1: 35-50. 
Mackie, G., F. Moneti, H. Shakya, and E. Denny. 2015. What are social norms? How are they measured?. New York and San Diego: UNICEF and University of California, San Diego, Center on Global Justice. Available at: https://www.unicef.org/protection/files/4_09_30_Whole_What_are_Social_Norms.pdf

Mehari, G. 2016. "Cursed or blessed: Female genital cutting in the Gamo cultural landscape, south western Ethiopia," Ahfad Journal 33(1): 3-15.

Miles, M. B., \& Huberman, A. M. (1994). Qualitative data analysis: An expanded sourcebook. sage.

Ministry of Finance and Economic Development (MFED) and Ministry of Women, Children and Youth Affairs (MWCYA), Ethiopia. 2013. Policy Brief: Abandoning FGM/C (Female Genital Mutilation/Cutting) in Ethiopia. Available at:

https://www.unicef.org/ethiopia/Abandoning_FGM_in_Ethiopia.pdf [accessed 30 August 2018].

Norwegian Church Aid (NCA). 2011. Norwegian Church Aids Ethiopia And Partners Achievement Report (2009-2011). Oslo: NCA.

2015. "Faith-Based Organisation's Response for the Abandonment of Female Genital Mutilation and Other Harmful Traditional Practices in Ethiopia: The Experience of NAl's Partners." Oslo: NCA.

Pankhurst, A. 2014. "Child Marriage and Female Circumcision (FGM/C): Evidence from Ethiopia." Policy Brief. London: Young Lives.

Powell, R.A. and M. Yussuf. 2018. "Changes in FGM/C in Somaliland: Medical Narrative Driving Shift in Types of Cutting." Evidence to End FGM/C: Research to Help Women Thrive. New York: Population Council.

Ramos, S., \& Boyle, G. J. 2001. Ritual and medical circumcision among Filipino boys: Evidence of post-traumatic stress disorder. Eds: Denniston GC, Hodges FM \& Milos MF. Understanding circumcision: A multidisciplinary approach to a multi-dimensional problem.

Shell-Duncan, B., A. Moreau, K. Wander, and S. Smith. 2019. "Reference Guide: Factorial Focus Group Analysis Methods for Studying Social Norm Change." Evidence to End FGM/C: Research to Help Girls and Women Thrive. New York: Population Council.

Shell-Duncan B. and C. Feldman-Jacobs. 2016. "A State-of-Art Synthesis of Female Genital Mutilation/Cutting: What Do We Know Now?" Evidence to End FGM/C: Research to Help Women Thrive. New York: Population Council..

Shell-Duncan, B., K. Wander, Y. Hernlund, and A. Moreau. 2011. "Dynamics of change in the practice of female genital cutting in Senegambia: Testing predictions of social convention theory," Social Science and Medicine 73: 1275-1283.

Spadacini, B. and P. Nichols. 1998. "Campaigning against female genital mutilation in Ethiopia using popular education," Gender \& Development 6(2): 44-52.

Spencer P. 2012. "When culture harms-A case study on female genital mutilation in Ethiopia and reverberations felt in a wider context from a political and ethical perspective." Masters thesis. Halmstad, Sweden: Halmstad University.

UNICEF. 2016. Female Genital Mutilation/Cutting: A Global Concern. New York: UNICEF.

World Health Organization (WHO). 2014. Female Genital Mutilation. Geneva: World Health Organization. 